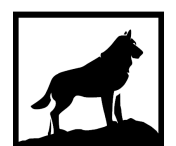

Michigan

Technological

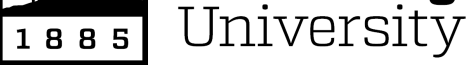

Michigan Technological University

Digital Commons @ Michigan Tech

ELEMENTARY ASSESSMENTS AND SIMULATIONS BASED

PROPOSALS FOR NEW HEAT TRANSFER CORRELATIONS AND FLOW REGIME MAPS FOR ANNULAR/STRATIFIED REGIME OF SHEAR DRIVEN INTERNAL CONDENSING FLOWS

Siddharth Ravikumar

Michigan Technological University, ravikuma@mtu.edu

Copyright 2015 Siddharth Ravikumar

Recommended Citation

Ravikumar, Siddharth, "ELEMENTARY ASSESSMENTS AND SIMULATIONS BASED PROPOSALS FOR NEW HEAT TRANSFER CORRELATIONS AND FLOW REGIME MAPS FOR ANNULAR/STRATIFIED REGIME OF SHEAR DRIVEN INTERNAL CONDENSING FLOWS", Open Access Master's Thesis, Michigan Technological University, 2015.

https://doi.org/10.37099/mtu.dc.etdr/44

Follow this and additional works at: https://digitalcommons.mtu.edu/etdr

Part of the Heat Transfer, Combustion Commons 


\title{
ELEMENTARY ASSESSMENTS AND SIMULATIONS BASED PROPOSALS FOR NEW HEAT TRANSFER CORRELATIONS AND FLOW REGIME MAPS FOR ANNULAR/STRATIFIED REGIME OF SHEAR DRIVEN INTERNAL CONDENSING FLOWS
}

\author{
By \\ Siddharth Ravikumar \\ A THESIS \\ Submitted in partial fulfillment of the requirements for the degree of \\ MASTER OF SCIENCE \\ In Mechanical Engineering
}

MICHIGAN TECHNOLOGICAL UNIVERSITY

2015

(C) 2015 Siddharth Ravikumar 
This thesis has been approved in partial fulfillment of the requirements for the Degree of MASTER OF SCIENCE in Mechanical Engineering.

Department of Mechanical Engineering-Engineering Mechanics

Thesis Advisor: $\quad$ Dr. Amitabh Narain

Committee Member: Dr. V.C Rao Komaravolu

Committee Member: $\quad$ Dr. Sunil Mehendale

Department Chair: $\quad$ Dr. William W. Predebon 


\section{Table of Contents}

List of Figures............................................................................

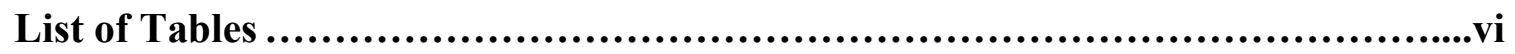

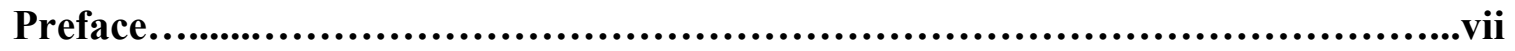

Acknowledgments.... ........................................................................................................viii

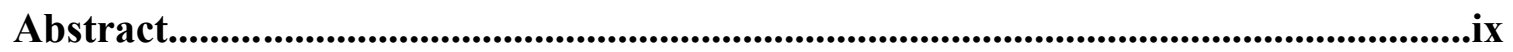

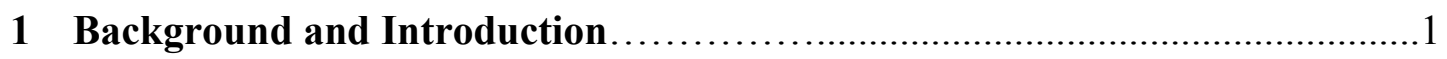

1.1 Purpose of this research and complications associated with internal

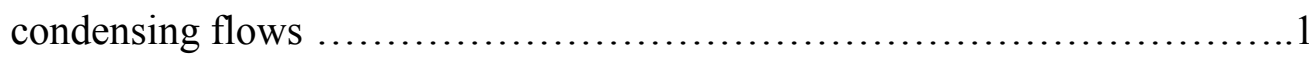

2 Physics Based Comprehension of Internal Shear Driven Condensing Flow...4

2.1 Governing Equations for Condensing Flows.............................. 9

$2.21 \mathrm{D}$ modelling and its Governing equations.............................. 12

2.3 Association of Non-Dimensional Parameters with Heat Transfer Correlations .14

2.4 Computational capabilities for shear driven internal condensing flows. .......19 
3 Semi-Empirical Engineering Heat Transfer Correlations and Flow Regime Maps for Shear/Pressure Driven Internal Condensing Flows................20

3.1 Engineering Heat Transfer Correlations in Literature... ...................20

3.1.1 Heat Transfer Correlation proposed by Kim and Mudawar..........21

4 Results, Discussions and Conclusions.......................................29

4.1 Computationally derived correlations for heat transfer rates, quality and length of annular regime.....................................29

4.1.1 Variation of Nusselt number as a function of non-dimensional

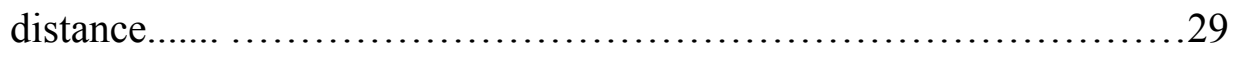

4.1.2 Prediction of the non-dimensional distance along the length of the condenser as a function of the flow variables......................30

4.1.3 Vapor quality's variations with non-dimensional distance...........31

4.1.4 Physics based support for correlations dependent on quality.........31

4.2 Conclusions and Subsequent Research.............................. 34

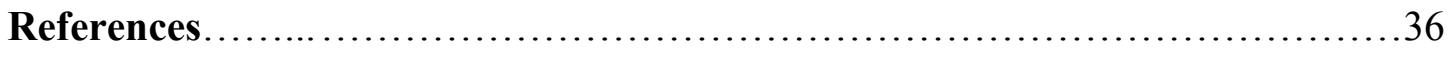




\section{List of Figures}

2.1 Schematic representation of shear driven Annular/Stratified internal condensing flow in rectangular cross-section channel..........................................

2.2 Symmetrically cooled internal condensing flow with condensation on both upper and

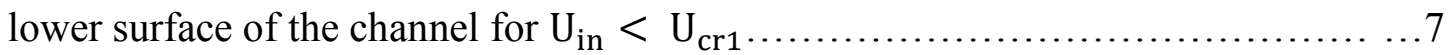

2.3 Symmetrically cooled internal condensing flow with condensation on both upper and

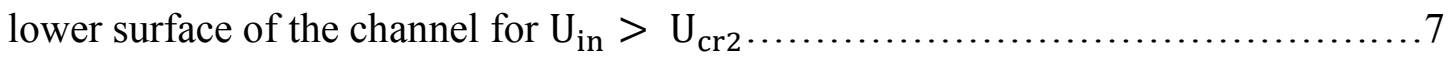

3.1 Representation of the variation of Nusselt Number with vapor quality for the above mentioned set of flow condition with FC72 as working fluid......................24

3.2 Representation of the variation of Vapor Quality with non-dimensional distance for the above mentioned set of flow condition with FC72 as working fluid.............24

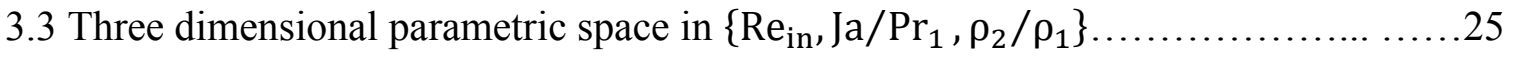

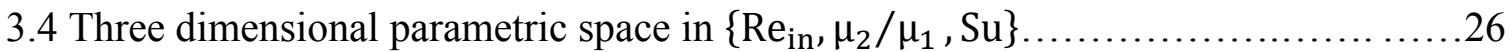

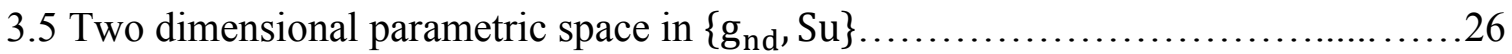

4.1 Variation of Nusselt Number along the non-dimensional length of the condenser....32

4.2 Variation of Vapor Quality along the non-dimensional length of the condenser ......33

4.3 Variation of Nusselt Number with the vapor quality................................33 


\section{List of Tables}

3.1 Range of raw fluid variables and flow conditions considered in this study.........27

3.2 Range of non-dimensional parameters associated with raw flow variables.........27 


\section{Preface}

This thesis would not have been achievable without the guidance provided by several individuals who extended their valuable encouragements towards the completion of this research. This thesis is a subpart of a journal publication by the research group of Dr. Amitabh Narain (my academic advisor) at Michigan Technological University. A major part of this thesis contains my work and contribution towards the publication of this journal paper [1]. This research would have never materialized without the constant motivation and goal driven approach of my advisor. Sincere efforts have been made to cite all the contributions of other co-authors as well. 


\section{Acknowledgements}

First and foremost, my utmost gratitude to Dr. Amitabh Narain for mentoring me, both academically and emotionally, throughout the course of this research. Without his ideas and support, this work would never have been doable.

I am grateful to Ranjeeth Naik, for helping me with the process of writing codes and implementation of research ideas. It would have been difficult for me to complete my research sooner, without his expertise with the research tools used in this study.

I am also thankful to Nikhil Shankar and Sharayu Bhasme for their collaboration in this study and for running 2D simulations for many cases required for this research.

I would also like to thank Dr. Sunil Mehendale for his valuable contribution towards the study initially when a lot of discussions were required before initiating the research. His efforts in compiling available engineering correlations relevant to this research helped further the research.

I would also like to thank Dr. KVC Rao for being a part of my defense committee and in helping me successfully complete this work on time.

I would like to thank all of my friends, especially Vinaya Sridhar and Aniruddha Bhide for helping me in successfully completing my research and in writing of my thesis.

Finally, I am thankful to my family, without their unconditional love and moral support I would not be successful in my life. 


\section{Abstract}

Contemporary cooling applications necessitate the use of mm-scale shear driven flow condenser designs which also need to ensure substantial heat transfer rates for a wide range of flow conditions. Some modern shear driven flow condensers must meet the requirements of small size and large heat flux removal capability for variety of flow conditions. For this, effective estimates of heat transfer rate correlations and correlations for estimating the length of the annular regime are essential. Existing heat transfer correlations are built based on semi-empirical approaches which are primarily supported by large data sets, which are often mixed with insufficient explanation and also do not exhibit a direct relation to flow physics based modelling of condensing flows. Typical heat transfer correlations primarily eliminate the dependency of heat transfer coefficient on the method of cooling imposed on the cooling surface of the condenser. These correlations are typically reported in terms of vapor quality, on which the heat transfer coefficient depends. Correlations based on quality instead of physical distance are preferred because the rest depends on the "method of cooling". The energy balance equation is then used to obtain a spatial variation of vapor quality along the length of the condenser. However, in fundamental physics based approaches, heat transfer coefficients are significantly dependent on thermal boundary conditions. This study focuses on bridging the knowledge gap between the semi-empirical approaches of typical correlations in literature and the direct flow physics based fundamental results from 
theory, computation and experiments. This study further explains the equivalency of physics based modelling to typical approach under certain conditions.

An important factor that needs vigilant observation on typical heat transfer correlations is the obscurity associated with the application of flow regime maps for internal condensing flows. Heat transfer rate is strongly influenced by the type of flow, but several heat transfer correlations are presented that cover several different flow regimes. This means correlations approach and data have to be good enough to accommodate significant variations in the correlated values of the heat transfer rates among different flow regimes. Flow regime maps in literature are also inaccurate because the assembled data from different experiments are examples of data on thermal boundary conditions and the downstream physical distances and quality where transitions are observed. This is believed to be true as these flow regime map data are not properly non-dimensionalized or have not been differentiated by suitable flow physics, further exacerbating their use for different flow applications. The key objective of this study (primarily restricted to shear driven annular flow regimes) is to establish the need for heat transfer correlations which are fundamentally (based on flow physics) constructed and compare their predictions with these obtained from correlations and flow regime maps existing in literature. This study also provides a basic structure for creating similar new correlations for various other flow types and regimes. For annular flows this is done by using two numerical tools, one which is highly efficient but in an approximate flow simulation tool (A Quasi 1-D Simulation tool [2]) and a nearly exact 2-D steady/unsteady simulation tool [3]. 


\section{Background and Introduction}

\subsection{Purpose of this research and complications associated with internal condensing flows}

Ever-increasing heat loads of high power consumption electronics industry demand new thermal management systems (condensers and boilers) of reduced mass and size to control the temperature of the device and to efficiently carry the heat away to ambient [4, 5]. Various thermal management technologies have been proposed to address the issues faced in high performance cooling applications and in certain space/aviation based applications. Among these technologies, phase change flows have exhibited tremendous potential to remove large amounts of heat generated by some of these high performance applications. This study focuses on developing innovative flow condensers and flow boilers, i.e. phase change flow devices that operate under shear pressure driven conditions with negligible effects of gravity. Flow condensers and boilers can be classified based on various conditions defining its configurations, primary driving force, and the type of working fluid.

Gravity driven or gravity dominated flows are typical macro scale flows in which the operating configuration of the flow condenser or boiler is vertical or inclined corresponding to Earth's gravitational vector. The orientation of these condenser provides more stability to the condensing liquid flow and lengthens the regime of stratified/annular operation. High heat transfer rates are achieved in the stratified/annular flow regime as the liquid condensate is always in immediate contact to the heat exchange surface of the 
condensers, yielding lower resistance to the flow of heat. A large number of published results $[2,6]$ substantiate the facts that gravity driven flows are more stable, and essentially occur in the annular/stratified flow regime.

On the other hand, in the absence of gravity along the flow direction in internal condensing flows, the liquid condensate is essentially driven by the interfacial shear forces between the inlet vapor and the liquid film- the reason for naming it as shear driven flows. Modern micro or millimeter scale condensers operated in high power electronics industry, gravity insensitive aircraft, or space based applications-all require shear driven flows in boilers and/or condensers. Since the force of gravity is negligible and the interfacial forces are preeminent, it readily causes complicated non annular flow regimes for a considerable portion of the condenser which adversely affect the heat transfer rates and effectiveness of the condensers. Experimental investigations have been conducted upon these ineffectual non-annular flow regimes such as plug flows, slug flows and bubbly flows (with certain variations in terminologies used for the flow regimes [7-12]). Since analogous flow regimes are observed in macro scale adiabatic flows [6-9, 12], vapor quality in addition to mass flux is a key variable used in developing heat transfer coefficient correlations and flow regime maps for both these flows. This research addresses base design needs of millimeter scale condensers operated in shear driven non-pulsatile steady conditions. It should be noted that Dr. Narain's research group has also established results for condensers and boilers operated in pulsatile mode, the rationale being development of next generation thermal management systems $[13,14]$. 
One critical element in the design of internal flow condensers is interpreting the flow morphology, or liquid-vapor interface configurations, as they play a crucial role in influencing the heat and mass transfer rates. In order to achieve a high performance condenser, the length of annular/stratified regime on the flow surface of condensers has to be relatively extended to operate entirely in this regime. Proper identification of the flow transition zones assists in avoiding the circumstances e.g., through changing the forming recirculating vapor flow rate [13-15] associated with annular to non-annular flow transitions. Such innovative condensers have been proposed [13-15] for annular/stratified operation along the entire length of the condenser. However, rudimentary estimates of the transitions can be obtained through the existing flow regime maps $[7-9,12]$, but they have to be non-dimensionalized and extended properly in an acceptable way to make them useful for various operating conditions and working fluids. This research provides a structured approach in assessing the efficacy of existing semiempirical heat transfer correlations $[11,16-18]$ and further assists in the development of such correlations for other flow regimes. Furthermore, results from existing study are compared with results obtained and proposed in the study using an approximate Quasi 1D [2] condensing flow simulation tool with a combination of experimental data $[13,14]$ and nearly exact 2D steady/unsteady simulation tools [3, 19-21]. 


\section{Physics Based Comprehension of Internal Shear Driven Condensing Flows}

This study primarily addresses the concerns associated with the development of shear driven condensers such as high heat flux removal in millimeter scale condensers for zero gravity/space based applications. This requirement of high performance condensers require controlled lengthening of the annular/stratified flow regime of a shear driven condensing flows. Therefore this study predominantly focuses on internal shear driven annular/stratified flow condensation in a horizontal (zero gravity flows) or annular flows inside a channel or a circular tube. Fig. 2.1 depicts internal condensing flow configurations inside a channel, where condensation occurs on the bottom wall and the film remains persistently annular over the entire length of the condenser under consideration. 


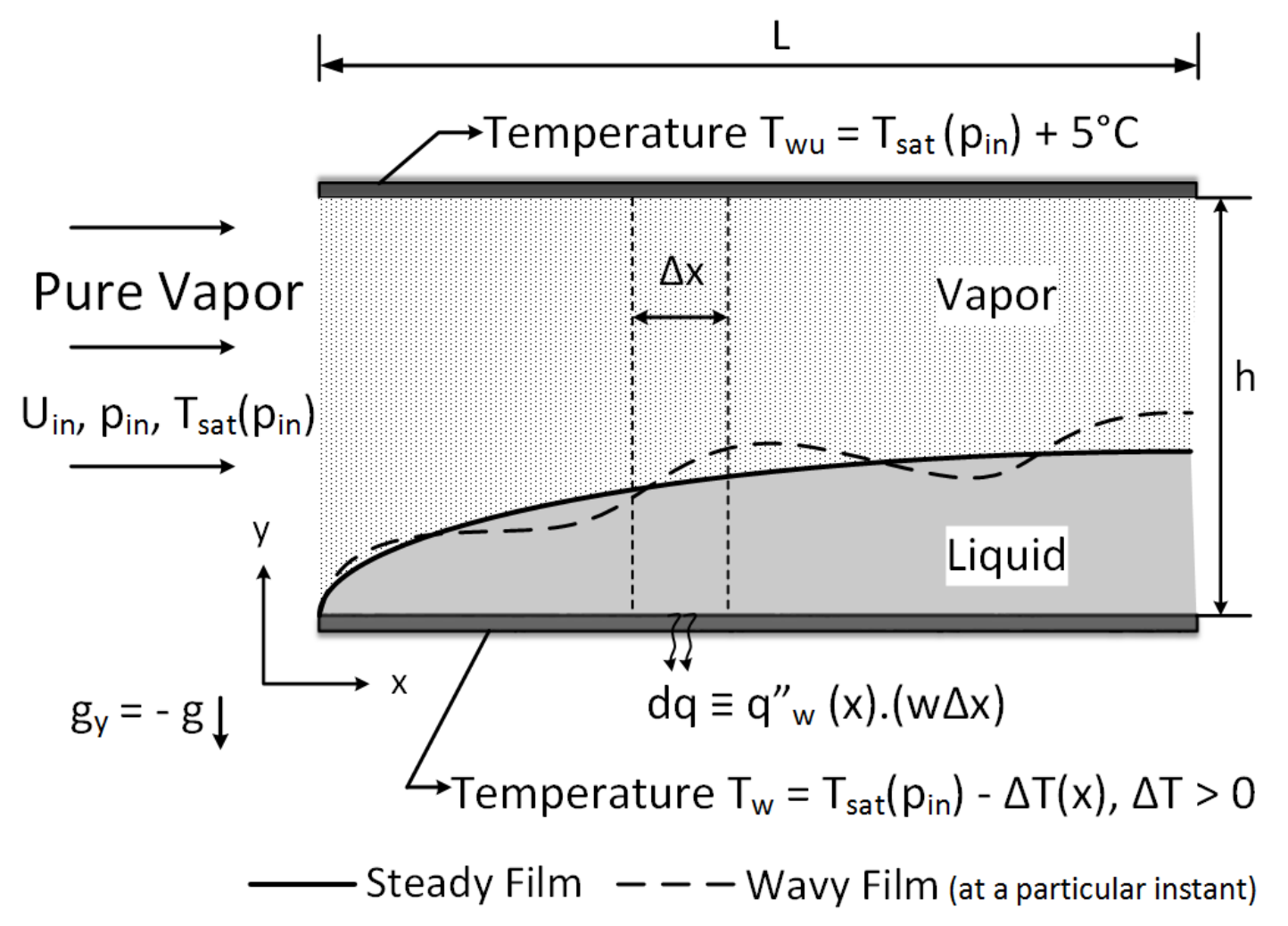

Figure 2.1 Schematic representation of shear driven Annular/Stratified internal condensing flow in rectangular cross-section channel

Pure vapor of the refrigerant at an inlet pressure $p_{\text {in }}$ and at the corresponding saturation temperature $T_{\text {sat }}\left(p_{\text {in }}\right)$ flows into the duct with an inlet velocity $U_{\text {in. }}$. The bottom wall is maintained at a temperature $\mathrm{T}_{\mathrm{w}}(\mathrm{x})$ which is lower than the saturation temperature. The upper surface is maintained at a slightly higher temperature above the saturation temperature. This results in condensation only in the lower wall. However if the upper surface wall temperature is altered to be equal to lower surface temperature, then condensation will occur on both the walls. In such cases, the inlet vapor velocity $U_{\text {in }}$ plays a crucial role in determining the flow regime across the condenser. For instance 
when inlet vapor velocities are less than a critical value $\mathrm{U}_{\mathrm{cr} 1}$, film wise condensation on the upper surface of the condenser is not realized because, the fluid flow inside the condenser is highly susceptible to presence of transverse gravity. Fig. 2.2 depicts the dripping of liquid condensate from the upper surface of the condenser when the inlet vapor velocities are less than a certain critical value and such condition are also termed to be "stratified". This is because, if the wall temperature is high enough, gravity plays a supportive role in keeping the annular liquid on the bottom condenser surface. However, "annular" or "wavy annular" flows are said to be realized when the inlet vapor velocities are higher than a certain critical value of vapor speeds $U_{c r 2}$. Under these conditions (see Fig. 2.2) interfacial shear stress stabilizes the flow (despite the pressure of transverse gravity) and produces film wise condensation on both the surfaces of the condenser. Inlet speeds of vapor ranging between $\mathrm{U}_{\mathrm{cr} 1}$ and $\mathrm{U}_{\mathrm{cr} 2}$ is believed to be the "transition" zone where the condensing flow has sharp variations in defining flow features including annular length $\mathrm{x}_{\mathrm{A}}$. 


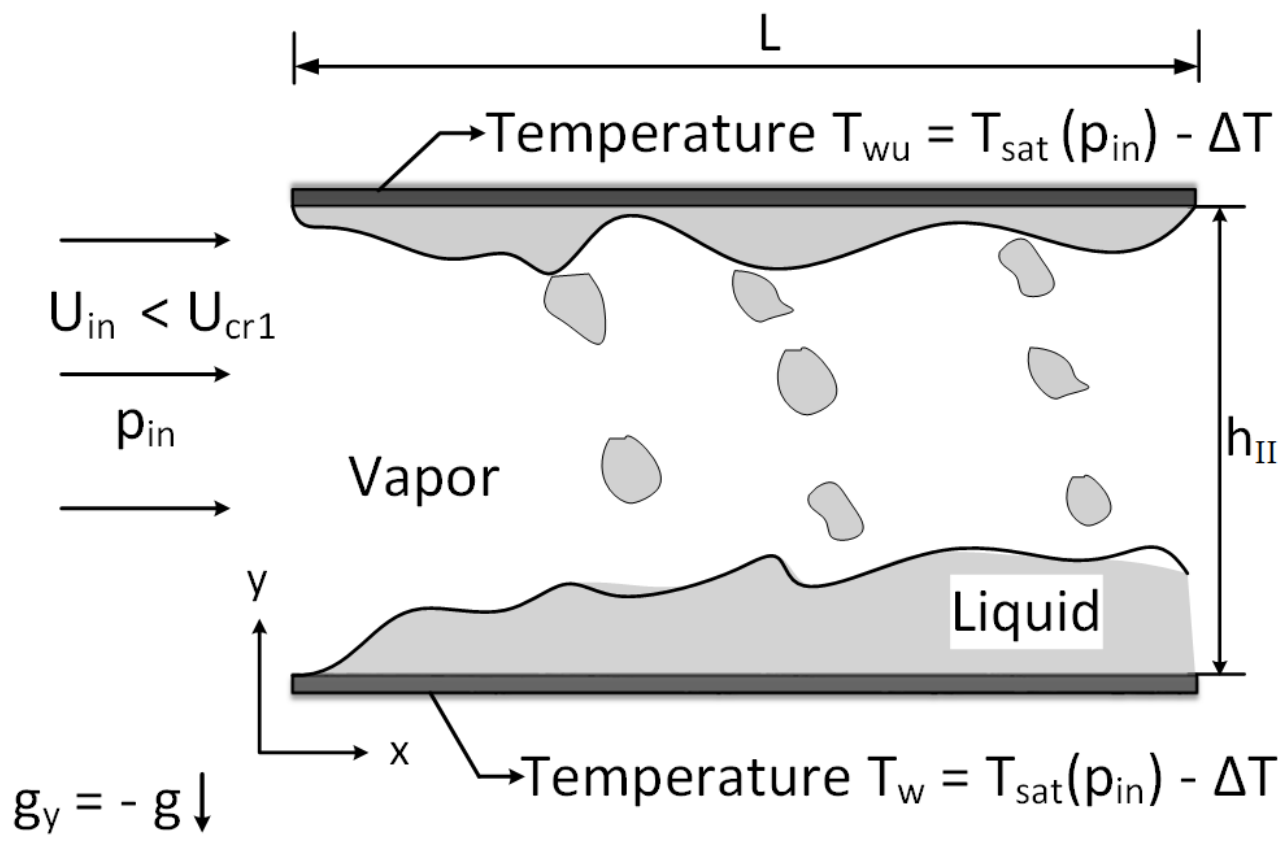

Figure 2.2 Symmetrically cooled internal condensing flow with condensation on both upper and lower surface of the channel for $\mathrm{U}_{\mathrm{in}}<\mathrm{U}_{\mathrm{cr} 1}$

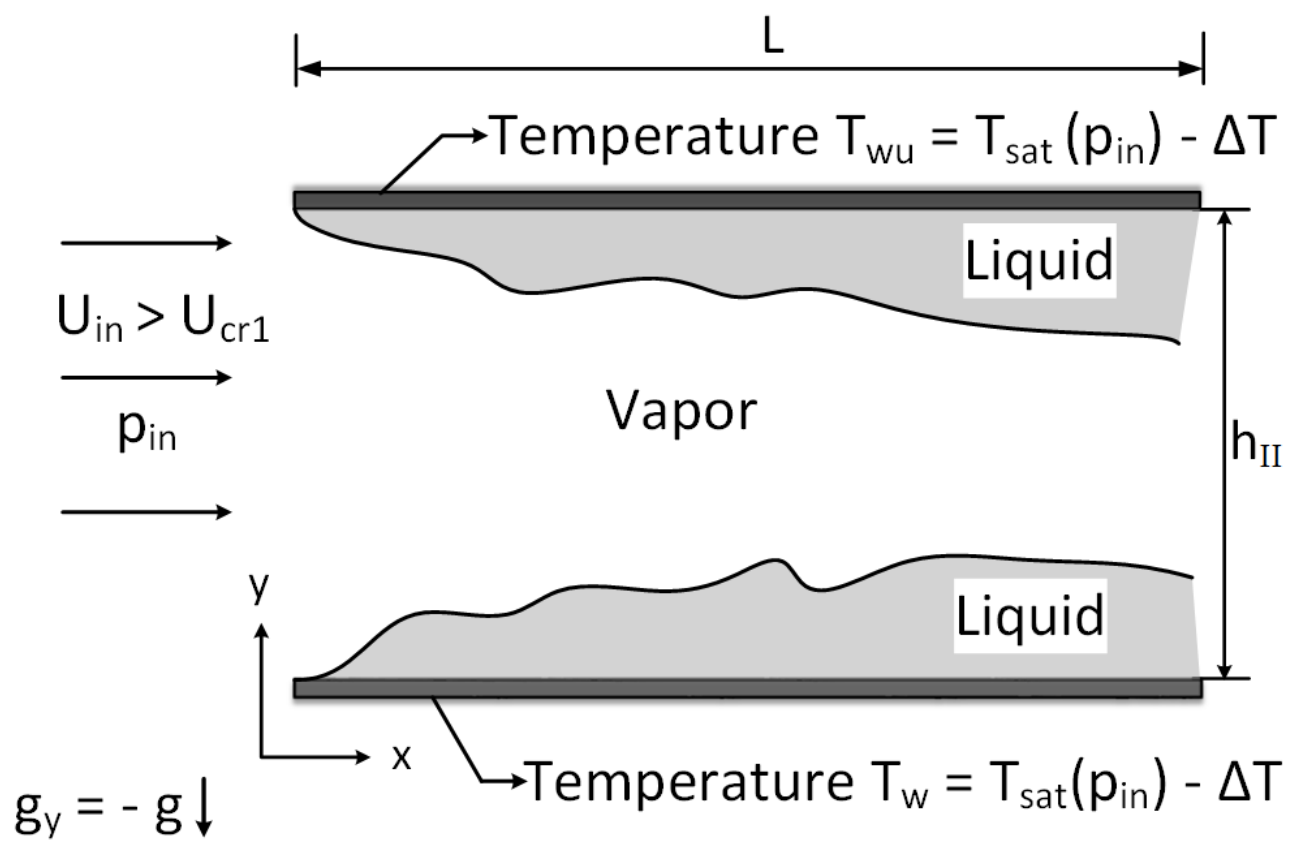

Figure 2.3 Symmetrically cooled internal condensing flow with condensation on both upper and lower surface of the channel for $U_{\text {in }}>U_{c r 2}$ 
The conventional flow variables in the liquid and vapor phases of the condensing flows illustrated above are denoted with the subscript I (where I = 1 for the liquid phase and $\mathrm{I}=2$ for the vapor phase). In the rudimentary modeling of the flow condensation, intrinsic fluid properties for each phase of the fluid are: the fluid density $\rho$, dynamic viscosity $\mu$, specific heat $C_{p}$ and thermal conductivityk. These fluid properties are surmised to remain approximately consistent for each phase $(I=1$ or $I=2)$ over the entire length of the condenser under consideration. The flow variables are designated as follows:

- Inlet flow velocity $U_{\text {in }}$

- Inlet pressure $\mathrm{p}_{\text {in }}$

- Inlet temperature $\mathrm{T}_{\mathrm{sat}}\left(\mathrm{p}_{\text {in }}\right)$

- Temperature fields $T_{I}(I=1$ or 2$)$

- Pressure fields $p_{I}$

- Velocity fields $\vec{V}_{I}=u_{I} \hat{\imath}+v_{I} \hat{\jmath}$ (where $\hat{\imath}$ and $\hat{\jmath}$ are unit vectors along the $\mathrm{x}$ and $\mathrm{y}$ axes)

- Film thickness $\Delta$

- Local interfacial mass flux per unit area $\dot{m}$

- Wall temperature function $\mathrm{T}_{\mathrm{w}}(\mathrm{x})$ - used in defining the "method of cooling" 
- Spatially averaged temperature $\overline{T_{w}} \equiv \int_{0}^{L} T_{w}(x) d x / L$

- Mean temperature difference $\overline{\Delta \mathrm{T}} \equiv \mathrm{T}_{\text {sat }}\left(\mathrm{p}_{\text {in }}\right)-\overline{\mathrm{T}_{\mathrm{w}}}$

For the variables specified above, the "method of cooling" is defined by the

function $\phi(\mathrm{x}) \equiv \Delta \mathrm{T}(\mathrm{x}) / \overline{\Delta \mathrm{T}}$. For all cooling in which, $\mathrm{T}_{\mathrm{w}}(\mathrm{x})=\overline{\mathrm{T}_{\mathrm{w}}}=$ constant over $0 \leq$ $\mathrm{x} \leq \mathrm{L}$, the "method of cooling" is same and is characterized by the constant function $\phi(x)=1$.

\subsection{Governing Equations for Condensing Flows}

Steady, incompressible, two dimensional governing equations of the form of differential equations for mass, momentum and energy balance are solved (see $[2,3])$ for the flow variables within each phase $(\mathrm{I}=1$ or $\mathrm{I}=2)$ of the condensing flow. The nondimensional representation of these equations are defined as follows [22]:

Incompressible differential mass balance equation:

$\frac{\partial \mathrm{u}_{\mathrm{I}}}{\partial \hat{\mathrm{x}}}+\frac{\partial \mathrm{v}_{\mathrm{I}}}{\partial \widehat{\mathrm{y}}}=0$

Momentum balance equations:

X component:

$\mathrm{u}_{\mathrm{I}} \frac{\partial \mathrm{u}_{\mathrm{I}}}{\partial \widehat{\mathrm{x}}}+\mathrm{v}_{\mathrm{I}} \frac{\partial \mathrm{u}_{\mathrm{I}}}{\partial \widehat{\mathrm{y}}}=-\left(\frac{\partial \pi_{\mathrm{I}}}{\partial \hat{\mathrm{x}}}\right)+\mathrm{Fr}_{\mathrm{x}}^{-1}+\operatorname{Re}_{\mathrm{I}}^{-1}\left(\frac{\partial^{2} \mathrm{u}_{\mathrm{I}}}{\partial \hat{\mathrm{x}}^{2}}+\frac{\partial^{2} \mathrm{u}_{\mathrm{I}}}{\partial \widehat{\mathrm{y}}^{2}}\right)$ 


\section{Y component:}

$\mathrm{u}_{\mathrm{I}} \frac{\partial \mathrm{v}_{\mathrm{I}}}{\partial \hat{\mathrm{x}}}+\mathrm{v}_{\mathrm{I}} \frac{\partial \mathrm{v}_{\mathrm{I}}}{\partial \widehat{\mathrm{y}}}=-\left(\frac{\partial \pi_{\mathrm{I}}}{\partial \widehat{\mathrm{y}}}\right)+\mathrm{Fr}_{\mathrm{y}}^{-1}+\mathrm{Re}_{\mathrm{I}}^{-1}\left(\frac{\partial^{2} \mathrm{v}_{\mathrm{I}}}{\partial \hat{\mathrm{x}}^{2}}+\frac{\partial^{2} \mathrm{v}_{\mathrm{I}}}{\partial \widehat{\mathrm{y}}^{2}}\right)$

Energy balance equation:

$\mathrm{u}_{\mathrm{I}} \frac{\partial \theta_{\mathrm{I}}}{\partial \hat{\mathrm{x}}}+\mathrm{v}_{\mathrm{I}} \frac{\partial \theta_{\mathrm{I}}}{\partial \widehat{\mathrm{y}}}=\operatorname{Re}_{\mathrm{I}}^{-1} \operatorname{Pr}_{\mathrm{I}}^{-1}\left(\frac{\partial^{2} \theta_{\mathrm{I}}}{\partial \hat{\mathrm{x}}^{2}}+\frac{\partial^{2} \theta_{\mathrm{I}}}{\partial \widehat{\mathrm{y}}^{2}}\right)$

where $\operatorname{Re}_{\mathrm{I}} \equiv \rho_{\mathrm{I}} \mathrm{U}_{\mathrm{in}} \mathrm{h} / \mu_{\mathrm{I}}, \operatorname{Pr}_{\mathrm{I}} \equiv \mu_{\mathrm{I}} \mathrm{C}_{\mathrm{pI}} / \mathrm{k}_{\mathrm{I}}, \mathrm{Fr}_{\mathrm{x}}^{-1} \equiv \mathrm{g}_{\mathrm{x}} \mathrm{h} / \mathrm{U}_{\text {in }}^{2}$ and $\mathrm{Fr}_{\mathrm{y}}^{-1} \equiv \mathrm{g}_{\mathrm{y}} \mathrm{h} / \mathrm{U}_{\mathrm{in}}^{2}$.

These equations also contain the body force parameters associated to be acceleration due to gravity along the $\mathrm{x}$ and $\mathrm{y}$ axes of the condenser. Since this study is only interested in flow condensers for micro gravity applications, gravity parameters $\mathrm{Fr}_{\mathrm{x}}^{-1}$ and $\mathrm{Fr}_{\mathrm{y}}^{-1}$ will always be equal or nearly equal to zero. The time varying variables have been dropped from the above governing equations, enabling them to model fully steady interior flows. The computational solution provided by these equations for each incompressible phase gives the tentative required values of variables within each phase. However, to correctly determine these flow variables and the location of liquid-vapor interface, it is required to solve an additional interface equation and repeat solving by the incompressible liquid vapor phases governing equations. These iterations are repeated until converges.

The accurate model for interface conditions [23] associated with the condensing flows for with the flow variables at the interface locations, are presented below:

i. Continuity equation for tangential components of velocities: 
$u_{2}^{\mathrm{i}}=\mathrm{u}_{2}^{\mathrm{i}}-\delta_{\hat{\mathrm{x}}}\left(\mathrm{v}_{2}^{\mathrm{i}}-\mathrm{v}_{1}^{\mathrm{i}}\right)$

where $\delta_{\hat{\mathrm{x}}} \equiv \partial \delta / \partial \hat{\mathrm{x}}$

ii. Momentum balance in the normal component at the interface:

$\pi_{1}^{\mathrm{i}}=\frac{\rho_{2}}{\rho_{1}} \pi_{2}^{\mathrm{i}}-\mathrm{We}^{-1}\left(\frac{\delta_{\widehat{\mathrm{x}} \widehat{\mathrm{x}}}}{\left[1+\delta_{\widehat{\mathrm{X}}}^{2}\right]^{1.5}}\right)+\dot{\mathrm{m}}^{2}\left(\frac{\rho_{1}}{\rho_{2}}-1\right)$

where We $\equiv \rho_{1} \mathrm{U}_{\text {in }}^{2} \mathrm{~h} / \sigma$, and surface tension $\sigma=\sigma(\mathcal{T})$ where $\mathcal{T}$ is the temperature at the interface.

iii. Momentum balance in the tangential component at the interface:

$\left.\frac{\partial \mathrm{u}_{1}}{\partial \widehat{\mathrm{y}}}\right|^{\mathrm{i}}=\left.\frac{\mu_{2}}{\mu_{1}} \frac{\partial \mathrm{u}_{2}}{\partial \widehat{\mathrm{y}}}\right|^{\mathrm{i}}+[\mathrm{t}]$

The definition of term [t] is provided by Eq. (A.9) of [23]

iv. Non-zero interfacial mass fluxes $\widehat{\mathrm{m}}_{\mathrm{LK}}$ and $\widehat{\mathrm{m}}_{\mathrm{VK}}$ as defined in Eq. (A.5) of [23]:

$\widehat{\mathrm{m}}_{\mathrm{LK}}=\left(\mathrm{u}_{1}^{\mathrm{i}} \frac{\partial \delta}{\partial \hat{\mathrm{x}}}-\mathrm{v}_{1}^{\mathrm{i}}\right) / \sqrt{1+\left(\frac{\partial \delta}{\partial \hat{\mathrm{x}}}\right)^{2}}$

$\widehat{\mathrm{m}}_{\mathrm{VK}}=\left(\frac{\rho_{2}}{\rho_{1}} \mathrm{u}_{2}^{\mathrm{i}} \frac{\partial \delta}{\partial \hat{\mathrm{x}}}-\mathrm{v}_{2}^{\mathrm{i}}\right) / \sqrt{1+\left(\frac{\partial \delta}{\partial \hat{\mathrm{x}}}\right)^{2}}$

v. The interfacial mass flux $\widehat{\mathrm{m}}_{\text {energy }}$, as defined in Eq. (A.6) of [23]:

$\widehat{\mathrm{m}}_{\text {energy }} \equiv \frac{\mathrm{Ja}}{\operatorname{Re}_{1} \operatorname{Pr}_{1}}\left[\left.\frac{\partial \theta_{1}}{\partial \mathrm{n}}\right|^{\mathrm{i}}-\left.\left(\frac{\mathrm{k}_{2}}{\mathrm{k}_{1}}\right) \frac{\partial \theta_{2}}{\partial \mathrm{n}}\right|^{\mathrm{i}}\right]$ 
Here Ja $\equiv \mathrm{C}_{\mathrm{p} 1} \Delta \mathrm{T} / \mathrm{h}_{\mathrm{fg}}^{0}$ and $\mathrm{h}_{\mathrm{fg}}^{0} \equiv \mathrm{h}_{\mathrm{fg}}\left(\mathrm{T}_{\mathrm{sat}}\left(\mathrm{P}_{\mathrm{in}}\right)\right) \cong \mathrm{h}_{\mathrm{fg}}\left(\mathrm{T}_{\mathrm{sat}}\left(\mathrm{P}_{2}^{\mathrm{i}}\right)\right)$

vi. Mass balance at the interface:

$\widehat{\mathrm{m}} \equiv \widehat{\mathrm{m}}_{\mathrm{LK}}=\widehat{\mathrm{m}}_{\mathrm{VK}}=\widehat{\mathrm{m}}_{\mathrm{energy}}$

vii. The thermodynamic restriction on the interfacial temperatures as in Eq. (A.8) of [23]:

$\theta_{1}^{\mathrm{i}} \cong \theta_{2}^{\mathrm{i}}=\frac{\mathrm{T}_{\mathrm{sat}}\left(\mathrm{P}_{2}^{\mathrm{i}}\right)-\overline{\mathrm{T}_{\mathrm{w}}}}{\Delta \mathrm{T}} \equiv \theta_{\text {sat }}\left(\pi_{2}^{\mathrm{i}}\right)$

Small changes in pressure (relative to inlet pressure) of the vapor phase within the condenser significantly influences vapor motion because vapors are of low density and low viscosity. But such small variations when compared to the inlet pressure of the flow do not influence saturation temperature variations significantly. Hence $\mathrm{T}_{\text {sat }}\left(\mathrm{P}_{2}^{\mathrm{i}}\right) \cong$ $\mathrm{T}_{\text {sat }}\left(\mathrm{P}_{\mathrm{in}}\right)$ is a good approximation.

\subsection{D Modelling and Governing Equations}

Popular 1D approximation techniques in literature incorporate empirical models (turbulence models, pressure gradient models etc.) and use several averaged values of the flow variables. However the 1D approximation technique followed in this study [2] uses exact analytical functions for the condensing flow by making a single approximation for the vapor profile $u_{2}(\hat{x}, \hat{y})$ with regards to its cross sectional variation. Next integral 
forms of vapor phase momentum and vapor phase mass balance alone are used [2], while naturally utilizing the analytical solution of the nearly flat, thin film, boundary layer type differential model as an approximate set of governing equation for liquid domain. Thus for the liquid domain the basic $2 \mathrm{D}$ governing equations are then simplified to the following (based on the above assumptions):

$0 \cong \mathrm{u}_{1} \frac{\partial \mathrm{u}_{1}}{\partial \hat{\mathrm{x}}}+\mathrm{v}_{1} \frac{\partial \mathrm{v}_{1}}{\partial \hat{\mathrm{x}}} \cong \frac{1}{\mathrm{Re}_{1}} \frac{\partial^{2} \mathrm{u}_{1}}{\partial \hat{\mathrm{x}}^{2}}-\frac{\partial \pi_{1}}{\partial \hat{\mathrm{x}}}+\mathrm{Fr}_{\mathrm{x}}^{-1}$

$0 \cong \frac{\partial \pi_{1}}{\partial \widehat{y}}-\mathrm{Fr}_{\mathrm{y}}^{-1}$

$0 \cong \frac{1}{\operatorname{Re}_{\mathrm{I}} \operatorname{Pr}_{\mathrm{I}}}\left(\frac{\partial^{2} \theta_{I}}{\partial \widehat{y}^{2}}\right)$

The above being the momentum $(2.13,2.14)$ and energy $(2.15)$ balance equations respectively. The interfacial conditions are also simplified as follows:

$$
\begin{aligned}
& \mathrm{u}_{2}^{\mathrm{i}}=\mathrm{u}_{1}^{\mathrm{i}}=\mathrm{u}_{\mathrm{f}}(\hat{\mathrm{x}}) \\
& \pi_{1}^{\mathrm{i}}=\frac{\rho_{2}}{\rho_{1}} \pi_{2}^{\mathrm{i}}=\frac{\rho_{2}}{\rho_{1}} \pi(\hat{\mathrm{x}}) \\
& \left.\frac{\partial \mathrm{u}_{1}}{\partial \widehat{y}}\right|^{\mathrm{i}}=\left.\frac{\mu_{2}}{\mu_{1}} \frac{\partial \mathrm{u}_{2}}{\partial \widehat{y}}\right|^{\mathrm{i}} \\
& \widehat{\mathrm{m}}_{\text {energy }} \cong \frac{\mathrm{Ja}}{\operatorname{Re}_{1} \operatorname{Pr}_{1}}\left(\left.\frac{\partial \theta_{1}}{\partial \widehat{y}}\right|^{\mathrm{i}}\right)
\end{aligned}
$$




\subsection{Association of Non- Dimensional Parameters with Heat Transfer Correlations}

The shear driven annular/ stratified flow of interest can be realized with the following non-dimensionalization of flow variables. As mentioned in Fig. (2.1), the physical variables associated with the condensers are;

- Length of the channel ' $L$ '

- Height of the channel ' $h$ '

- Width of the channel ' $\mathrm{w}$ '

- Cross-sectional area of the duct ' $\mathrm{A}_{\mathrm{c}}$ '

- Wetted perimeter ' $\mathrm{P}_{\mathrm{w}}$ '

- Hydraulic diameter ' $\mathrm{D}_{\mathrm{h}} \equiv 4 \mathrm{~A}_{\mathrm{c}} / \mathrm{P}_{\mathrm{w}}$ '

For the flow under consideration, at any given location ' $x$ ' along the length of the condenser, the mass balance of liquid control volume along the length of the condenser can be stated as eq. (2.20), using the separate mass flow rates of the liquid $\left(\dot{\mathrm{M}}_{\mathrm{L}}(\mathrm{x})\right)$ and vapor $\left(\dot{\mathrm{M}}_{\mathrm{V}}(\mathrm{x})\right)$ phases.

$\dot{\mathrm{M}}_{\mathrm{in}} \equiv \dot{\mathrm{M}}_{\mathrm{L}}(\mathrm{x})+\dot{\mathrm{M}}_{\mathrm{V}}(\mathrm{x})$

As mentioned earlier, vapor quality can be defined as the ratio of vapor or gas-phase mass flow rate to total mass flow rate and can be realized as: 
$\mathrm{X}(\mathrm{x}) \equiv \dot{\mathrm{M}}_{\mathrm{V}}(\mathrm{x}) / \dot{\mathrm{M}}_{\mathrm{in}}$

The above definition is related to and can be close to the thermodynamic quality used in obtaining experimental correlations. The closeness depends on how accurately the experiment knows the location where $\mathrm{X}(\mathrm{x})=1$ or 0 i.e. where mean vapor temperature (in case of condensers) or liquid temperature (in case of boiling) equals saturation temperature.

Further comparing Eq. (2.21) with the mass balance Eq. (2.20) we can conclude:

$\dot{\mathrm{M}}_{\mathrm{L}}(\mathrm{x}) / \dot{\mathrm{M}}_{\text {in }} \equiv 1-\mathrm{X}(\mathrm{x})$

From the simplified energy balance Eq. (2.15) applied to the liquid control volume in Fig. 2.1 one can obtain:

$\dot{\mathrm{M}}_{\mathrm{in}} \cdot \frac{\mathrm{dX}(\mathrm{x})}{\mathrm{dx}} \cdot \mathrm{h}_{\mathrm{fg}}=-\left\{\mathrm{h}_{\mathrm{x}} \cdot \Delta \mathrm{T}\right\} \mathrm{w} \cdot \phi(\mathrm{x})$

Using earlier and forthcoming discussions on non-dimensionalization of the flow variables, introducing $\hat{\mathrm{x}} \equiv \mathrm{x} / \mathrm{h}$ and other non-dimensional parameters and simplifying the above equation (while continuing to demand satisfaction of mass balance and momentum balance through use of experimental data) becomes:

$\frac{\mathrm{dX}(\hat{\mathrm{x}})}{\mathrm{d} \hat{\mathrm{x}}}=-\mathrm{Nu}_{\mathrm{x}} \cdot \frac{\mathrm{Ja}}{\mathrm{Re}_{\mathrm{in}} \cdot \mathrm{Pr}_{1}} \cdot \frac{\mu_{1}}{\mu_{2}} \phi(\mathrm{x})$

where $\mathrm{X}(0)=1$. But, because of a typical singularity (infinite value) in $\mathrm{Nu}_{\mathrm{x}}$ correlations at $\mathrm{X} \approx 1$, it is best to solve the above with suitably chosen $\varepsilon>0$ but $\varepsilon \approx 0$ that require $\mathrm{X}(\varepsilon)$ 
$=\mathrm{X}^{*}$, where $\mathrm{X}^{*}$ is close to 1 (say 0.99 ). Substitution of dependence (2.31), to be discussed in the above equation yields,

$X(\hat{\mathrm{X}})=\mathrm{X}\left(\hat{\mathrm{X}}, \operatorname{Re}_{\mathrm{in}} ; \frac{\mathrm{Ja}}{\operatorname{Pr}_{1}}, \frac{\rho_{2}}{\rho_{1}}, \frac{\mu_{2}}{\mu_{1}}\right)$

The variation of heat flux is influenced by the flow geometry, average inlet speed, fluid properties of each phase, and cooling conditions (boundary conditions). Here the vapor's thermal conductivity and specific heat does not influence the wall heat flux significantly and therefore the variation of heat flux can be represented by the following equation:

$$
\begin{aligned}
\mathrm{q}_{\mathrm{w}}^{\prime \prime}(\mathrm{x}) & \equiv \mathrm{h}_{\mathrm{x}}\left\{\mathrm{T}_{\mathrm{sat}}\left(\mathrm{p}_{\text {in }}\right)-\overline{\mathrm{T}_{\mathrm{w}}}\right\} \\
& \equiv \mathrm{h}_{\mathrm{x}} \cdot \overline{\Delta \mathrm{T}}
\end{aligned}
$$

The local heat transfer coefficient $h_{x}$, mentioned above is directly dependent on several physical parameters which include the parameters stated above for the heat flux and this dependence can be represented as:

$\mathrm{h}_{\mathrm{x}} \equiv \mathrm{h}_{\mathrm{x}}\left(\mathrm{x}, \mathrm{U}_{\mathrm{in}}, \Delta \mathrm{T}, \rho_{1}, \rho_{2}, \mu_{1}, \mu_{2}, \mathrm{C}_{\mathrm{p}_{1}}, \mathrm{k}_{1}, \mathrm{~h}_{\mathrm{fg}},\left|\mathrm{g}_{\mathrm{y}}\right|, \sigma\right)$

The length of annular regime needs to be predicted for proper designing of condensers along with the prediction of heat load requirements. Since the length of the annular regime is primarily dependent on the flow itself, the factors influencing the length would be similar to the variables affecting the local heat transfer coefficient and can be said to be: 
$\mathrm{x}_{\mathrm{A}} \equiv \mathrm{x}_{\mathrm{A}}\left(\mathrm{U}_{\mathrm{in}}, \Delta \mathrm{T}, \rho_{1}, \rho_{2}, \mu_{1}, \mu_{2}, \mathrm{C}_{\mathrm{p}_{1}}, \mathrm{k}_{1}, \mathrm{~h}_{\mathrm{fg}},\left|\mathrm{g}_{\mathrm{y}}\right|, \sigma\right)$

Proper non dimensionalization of flow variables is helpful in predicting and using heat transfer correlations for different flow conditions and fluids. This approach still allows a user to relate to the physical flow variables directly. The equations (2.27) \& (2.28) can be non-dimensionalized ( using Pi theorem [24] ) to the flowing form:

$$
\begin{aligned}
& \mathrm{Nu}_{\mathrm{x}} \equiv \frac{\mathrm{h}_{\mathrm{x}} \cdot \mathrm{h}}{\mathrm{k}_{1}}=\left.\mathrm{Nu}_{\mathrm{x}}\right|_{\mathrm{h}}=\widehat{\mathrm{fn}_{1}}\left(\widehat{\mathrm{x}}, \operatorname{Re}_{\mathrm{in}}, J \mathrm{Ja}, \operatorname{Pr}_{1}, \frac{\rho_{2}}{\rho_{1}}, \frac{\mu_{2}}{\mu_{1}}, \mathrm{~g}_{\mathrm{nd}}, \mathrm{Su}\right) \\
& \hat{\mathrm{x}}_{\mathrm{A}}=\widehat{\mathrm{fn}_{2}}\left(\operatorname{Re}_{\mathrm{in}}, J \mathrm{Ja}, \operatorname{Pr}_{1}, \frac{\rho_{2}}{\rho_{1}}, \frac{\mu_{2}}{\mu_{1}}, \mathrm{gnd}_{\mathrm{nd}}, \mathrm{Su}\right)
\end{aligned}
$$

where $\widehat{\mathrm{fn}_{1}}$ and $\widehat{\mathrm{fn}_{2}}$ are unknown functions that are to be experimentally and/or theoretically/computationally determined and are defined as:

- $\hat{\mathrm{x}} \equiv \mathrm{x} / \mathrm{h}$, non-dimensional downstream distance

- $\hat{\mathrm{x}}_{\mathrm{A}} \equiv \mathrm{x}_{\mathrm{A}} / \mathrm{h}$,

- $\mathrm{Nu}_{\mathrm{x}} \equiv \mathrm{h}_{\mathrm{x}} \cdot \mathrm{h} / \mathrm{k}_{1}$, local Nusselt number

- $\mathrm{Re}_{\text {in }} \equiv \rho_{2} \mathrm{U}_{\mathrm{in}} \mathrm{h} / \mu_{2}$, inlet Reynolds number

- $\mathrm{Ja} \equiv \mathrm{c}_{\mathrm{p}_{1}} \cdot \Delta \mathrm{T} / \mathrm{h}_{\mathrm{fg}}\left(\mathrm{p}_{\text {in }}\right)$, Jakob number

- $\operatorname{Pr}_{1} \equiv \mu_{1} \cdot \mathrm{c}_{\mathrm{p}_{1}} / \mathrm{k}$, Prandtl number

- $\mathrm{Su} \equiv \sigma \rho_{2} \mathrm{~h} / \mu_{2}^{2}$, Suratman number and 
- $\mathrm{g}_{\text {nd }}=\left|\mathrm{g}_{\mathrm{y}}\right| \rho_{2}{ }^{2} \mathrm{~h}^{3} / \mu_{2}^{2}$, non-dimensional transverse gravity number.

The parameter dependence of the non-dimensional form of heat transfer coefficient given in Eq. (2.29) may be in close agreement with the non-dimensional forms semi empirical heat transfer correlations existing in the literature and are discussed in detail in later chapters of this thesis. According to the interests of annular flow conditions considered for this research, the film thickness $\Delta(\mathrm{x})$ is relatively small with respect to the height ' $\mathrm{h}$ ' of the channel and, therefore, heat transfer by convection through the liquid condensate's motion can be ignored [2]. This leads to the assumption of linear temperature variations $[23,25]$ in the condensate and one can combine the individual dependences on Jakob and Prandtl numbers to the unified form of $\mathrm{Ja} / \mathrm{Pr}_{1}$. The impact of transverse gravity and the surface tension on the prediction of heat transfer coefficients and also length of the annular regime are considered in [3], detailed explanations are provided in subsequent sections. The above modelling focus simplifies Eqs. (2.29) \& (2.30) to the following:

$$
\begin{aligned}
& \mathrm{Nu}_{\mathrm{x}}=\widehat{\mathrm{fn}_{1}}\left(\widehat{\mathrm{x}}, \operatorname{Re}_{\mathrm{in}}, \frac{\mathrm{Ja}}{\operatorname{Pr}_{1}}, \frac{\rho_{2}}{\rho_{1}}, \frac{\mu_{2}}{\mu_{1}}\right) \\
& \hat{\mathrm{x}}_{\mathrm{A}} \equiv \mathrm{x}_{\mathrm{A}} / \mathrm{h}=\widehat{\mathrm{fn}_{2}}\left(\operatorname{Re}_{\mathrm{in}}, \frac{\mathrm{Ja}}{\operatorname{Pr}_{1}}, \frac{\rho_{2}}{\rho_{1}}, \frac{\mu_{2}}{\mu_{1}}, \mathrm{~g}_{\mathrm{nd}}, \mathrm{Su}\right)
\end{aligned}
$$

The prediction of heat transfer coefficients and the length of the annular regime being the main focus for proper design of the condensers/boilers (for high performance application in the electronics industry and other gravity insensitive applications), it is important to assess/analyze the existing correlations and flow regime maps that are widely accepted 
and to reformat them (for improving communications with those employing CFD simulation) to the above mentioned forms in Eqs. (2.31)-(2.32).

\subsection{Computational capabilities for shear driven internal condensing flows}

The results obtained in this study uses a highly efficient and sufficiently accurate quasi 1D flow simulation tool [2], and has been validated by comparing the results from correlation results obtained from the nearly exact 2D modelling and steady solutions [3, $19,20]$. Since results from $1 \mathrm{D}$ tool agrees well with results from the $2 \mathrm{D}$ steady tool, it justifies the earlier described 1D modelling approximations discussed earlier in this section. For this reason 1D approximation tool has been used as a supplement to the steady 2D simulation tool developed by the research group of Dr. Amitabh Narian at Michigan Technological University. This study does not include the details of the development of the code, although detailed description are given in [2].

For the $2 \mathrm{D}$ approach the interior equation of the liquid and the vapor phases are solved using COMSOL [26] (a Multiphysics tool) and the interfacial information through interface conditions are fed through MATLAB [27] (by Mathworks) based solution algorithms. The details of the formulation and implementation of these algorithms are discussed in detail in [2]. Consistency of the simulation results are explained in [3, 19, $20]$ and their equivalency with the experimental results are described in [13-15]. 


\section{Semi-Empirical Engineering Heat Transfer}

Correlations and Flow Regime Maps for Shear/Pressure

\section{Driven Internal Condensing Flows}

\subsection{Engineering Heat Transfer Correlations in Literature}

As mentioned in section 2, majority of the available engineering heat transfer correlations described in literature, specifically Kim and Mudawar [11], Shah et al. [17], Wang [18], Dobson and Chato [16] (which are primarily considered in this study), for shear/pressure driven internal condensing flows are shown to be equivalent to 1 or approximately so, the form:

$\left.\mathrm{Nu}_{\mathrm{x}}\right|_{\mathrm{D}_{\mathrm{h}}} \equiv \mathrm{h}_{\mathrm{x}} \cdot \mathrm{D}_{\mathrm{h}} / \mathrm{k}_{1}=\widetilde{\mathrm{fn}}\left(\mathrm{X}(\hat{\mathrm{x}}),\left.\operatorname{Re}_{\mathrm{in}}\right|_{\mathrm{D}_{\mathrm{h}}}, \frac{\rho_{2}}{\rho_{1}}, \frac{\mu_{2}}{\mu_{1}},\left.\mathrm{Su}\right|_{\mathrm{D}_{\mathrm{h}}}\right)$

In the above representation the characteristic length mentioned earlier is replaced by $\mathrm{D}_{\mathrm{h}}$ (hydraulic diameter). For shear driven condensing flows inside a tube the hydraulic diameter equals the tube diameter. Similar use of hydraulic diameter for the energy balance equation transformed $\mathrm{Eq}$ (2.23) to $\mathrm{Eq}$ (2.24), which is reproduced below

$\frac{\mathrm{dX}(\hat{\mathrm{x}})}{\mathrm{d} \hat{\mathrm{x}}}=-\left.N u_{\mathrm{x}}\right|_{\mathrm{D}_{\mathrm{h}}} \cdot \frac{\mathrm{Ja}}{\left.\mathrm{Re}_{\mathrm{in}}\right|_{\mathrm{D}_{\mathrm{h}}} \cdot \operatorname{Pr}_{1}} \cdot \frac{\mu_{1}}{\mu_{2}} \phi(\mathrm{x})$

From a first principles perspective, some existing correlations which use different non dimensional parameters may appear to neglect some parameters that influence the heat transfer rate in shear driven condensing flows. However solution of the above equation 
(3.2) a one dimensional energy balance equation, gives an explicit dependence of quality $\mathrm{X}$ on the downstream distance $\widehat{\mathrm{X}}$. A comparison argument indicating approximate equivalence of the fundamental equations and the semi empirical ones is possible. This is done by substituting existing acceptable $\mathrm{Nu}_{\mathrm{x}}$ correlations in the energy balance equation (3.2) and solving the resulting ODE, obtaining explicit forms of quality $X(\widehat{x})$ and comparing them for laminar- laminar annular cases- with 2D /1D predictions.

\subsubsection{Heat Transfer Correlation proposed by Kim and Mudawar}

Kim and Mudawar (2014) [11], put forward a universal approach for obtaining heat transfer correlation by summarizing the results observed in [11, 16-18]. The heat transfer coefficient proposed primarily focuses on mini and micro-channel flows for an extensive range of fluids. The correlations cover both stratified/annular as well as to nonannular flow regimes (plug/slug to bubbly flows). However their correlation proposed for stratified/annular to non-annular transition (as given in Eq. (3.3)) of shear driven internal condensing flows is discussed here because of its relevance to this study.

$\mathrm{Nu}_{\mathrm{x}} \equiv \frac{\mathrm{h}_{\mathrm{x}} \mathrm{D}_{\mathrm{hyd}}}{\mathrm{k}_{1}}=0.048 \mathrm{Re}_{1}^{0.69} \operatorname{Pr}_{1}^{0.34}\left(\frac{\phi_{\mathrm{g}}}{\mathrm{x}_{\mathrm{tt}}}\right)$

where,

$\mathrm{X}_{\mathrm{tt}}$, turbulent-turbulent Lockhart-Martinelli parameter defined as;

$\mathrm{X}_{\mathrm{tt}}=\left(\frac{\mu_{1}}{\mu_{2}}\right)^{0.1}\left(\frac{1-\mathrm{X}}{\mathrm{X}}\right)^{0.9}\left(\frac{\rho_{2}}{\rho_{1}}\right)^{0.5}$ 
$\phi_{\mathrm{g}}$, Two phase multiplier defined as;

$\phi_{\mathrm{g}}=1+\mathrm{CX}_{\mathrm{m}}+\mathrm{X}_{\mathrm{m}}^{2}$

C, Lockhart-Martinelli coefficient

$\mathrm{X}_{\mathrm{m}}$, Lockhart-Martinelli parameter [28] defined as;

$X_{m}=\left[\frac{(d p / d x)_{l i q}}{(d p / d x)_{v a p}}\right]^{1 / 2}$,

where $(\mathrm{dp} / \mathrm{dx})_{\text {liq }}$ and $(\mathrm{dp} / \mathrm{dx})_{\text {vap }}$ are the frictional pressure gradients of liquid and vapor phases respectively flowing alone in the pipe and computed using the following equations;

$$
\begin{aligned}
& \left(\frac{d p}{d x}\right)_{\text {liq }}=\frac{-2 f_{1} G^{2}(1-X)^{2}}{\rho_{1} D} \\
& \left(\frac{d p}{d x}\right)_{\text {vap }}=\frac{-2 f_{v} G^{2}(X)^{2}}{\rho_{2} D} \\
& f_{l}=B \operatorname{Re}_{1}^{-n} \\
& f_{v}=B \operatorname{Be}_{2}^{-n} \\
& \operatorname{Re}_{1}=\frac{G(1-X) D}{\mu_{1}} \\
& \operatorname{Re}_{v}=\frac{G X D}{\mu_{2}}
\end{aligned}
$$


$\mathrm{G}=\frac{4 \dot{\mathrm{M}}}{\pi \mathrm{D}_{\text {hyd }}^{2}}$

Friction factors $f_{v}$ and $f_{l}$ for vapor and liquid phases are respectively determined experimentally and their established correlations for round pipes are in the form of Eqs (3.1) - (3.10) which for laminar flows $(\operatorname{Re}<2000)$ have, $B=16$ and $n=1$ for and turbulent flows $(\operatorname{Re}>20000) \mathrm{B}=0.0079$ and $\mathrm{n}=0.25$.

For a representative condensing flow of FC-72 vapor, using FC 72 thermodynamic properties at $\mathrm{p}_{\mathrm{in}}=100 \mathrm{kPa}$, we create an argument list $\mathbf{A}\{$ Set $\mathrm{A} \equiv$ $\left(\mathrm{U}_{\mathrm{in}}, \mathrm{h}, \rho_{1}, \rho_{2}, \mu_{1}, \mu_{2}, \mathrm{c}_{\mathrm{p}_{1}}, \mathrm{k}_{1}, \mathrm{~h}_{\mathrm{fg}}, \Delta \mathrm{T}, \sigma\right)=\left(1 \mathrm{~m} / \mathrm{s}, 0.002 \mathrm{~m}, 1603 \mathrm{~kg} / \mathrm{m}^{3}, 13.06 \mathrm{~kg} / \mathrm{m}^{3}\right.$, $0.000494 \mathrm{~kg} / \mathrm{m}-\mathrm{s}, 1.16 \mathrm{e}-5 \mathrm{~kg} / \mathrm{m}-\mathrm{s}, 1.142 \mathrm{~kJ} / \mathrm{kg}-\mathrm{K}, 0.07041 \mathrm{~W} / \mathrm{mK}, 83.54 \mathrm{~kJ} / \mathrm{kg}, 15{ }^{\circ} \mathrm{C}$, $0.008329 \mathrm{~N} / \mathrm{m})$.$\} and obtain corresponding non-dimensional parameters NA \{$ Set NA $\equiv$ $\left.\left(\operatorname{Re}_{\mathrm{in}}, \mathrm{Ja} / \operatorname{Pr}_{1}, \rho_{2} / \rho_{1}, \mu_{2} / \mu_{1}, \mathrm{Su}\right)=(9006,0.0307,0.008,0.0234,6.44 \mathrm{e} 6)\right\}$. For comparison purpose we also introduce artificially modified property set $\mathbf{A}^{*}\left\{\right.$ Set $A^{*} \equiv$ $\left(\mathrm{U}_{\mathrm{in}}, \mathrm{h}, \rho_{1}, \rho_{2}, \mu_{1}, \mu_{2}, \mathrm{c}_{\mathrm{p}_{1}}, \mathrm{k}_{1}, \mathrm{~h}_{\mathrm{fg}}, \Delta \mathrm{T}, \sigma\right)=\left(0.833 \mathrm{~m} / \mathrm{s}, 0.0024 \mathrm{~m}, 1923.6 \mathrm{~kg} / \mathrm{m}^{3}, 15.672\right.$ $\mathrm{kg} / \mathrm{m}^{3}, 5.928 \mathrm{e}-4 \mathrm{~kg} / \mathrm{m}-\mathrm{s}, 1.39 \mathrm{e}-5 \mathrm{~kg} / \mathrm{m}-\mathrm{s}, 1.142 \mathrm{~kJ} / \mathrm{kg}-\mathrm{K}, 0.08449 \mathrm{~W} / \mathrm{m}-\mathrm{K}, 83.54 \mathrm{~kJ} / \mathrm{kg}$, $\left.\left.15{ }^{\circ} \mathrm{C}, 0.008329 \mathrm{~N} / \mathrm{m}\right)\right\}$ and its corresponding non-dimensional NA* $\{$ Set NA $\equiv$ $\left.\left(\operatorname{Re}_{\text {in }}, J a / \operatorname{Pr}_{1}, \rho_{2} / \rho_{1}, \mu_{2} / \mu_{1}, \mathrm{Su}\right)=(9006,0.0307,0.008,0.0234,6.44 \mathrm{e} 6)\right\}$. For these two sets, Kim and Mudawar correlation agree with one another's (see Fig. 3.1 - 3.2) as if they have the fundamental structure in Eq. (3.1). Figures 3.1- 3.2 can be said to verify our assertion that a correlation may appear to exhibit a different form but if it is approximately correct it will approximately satisfy Eq. (3.1). 


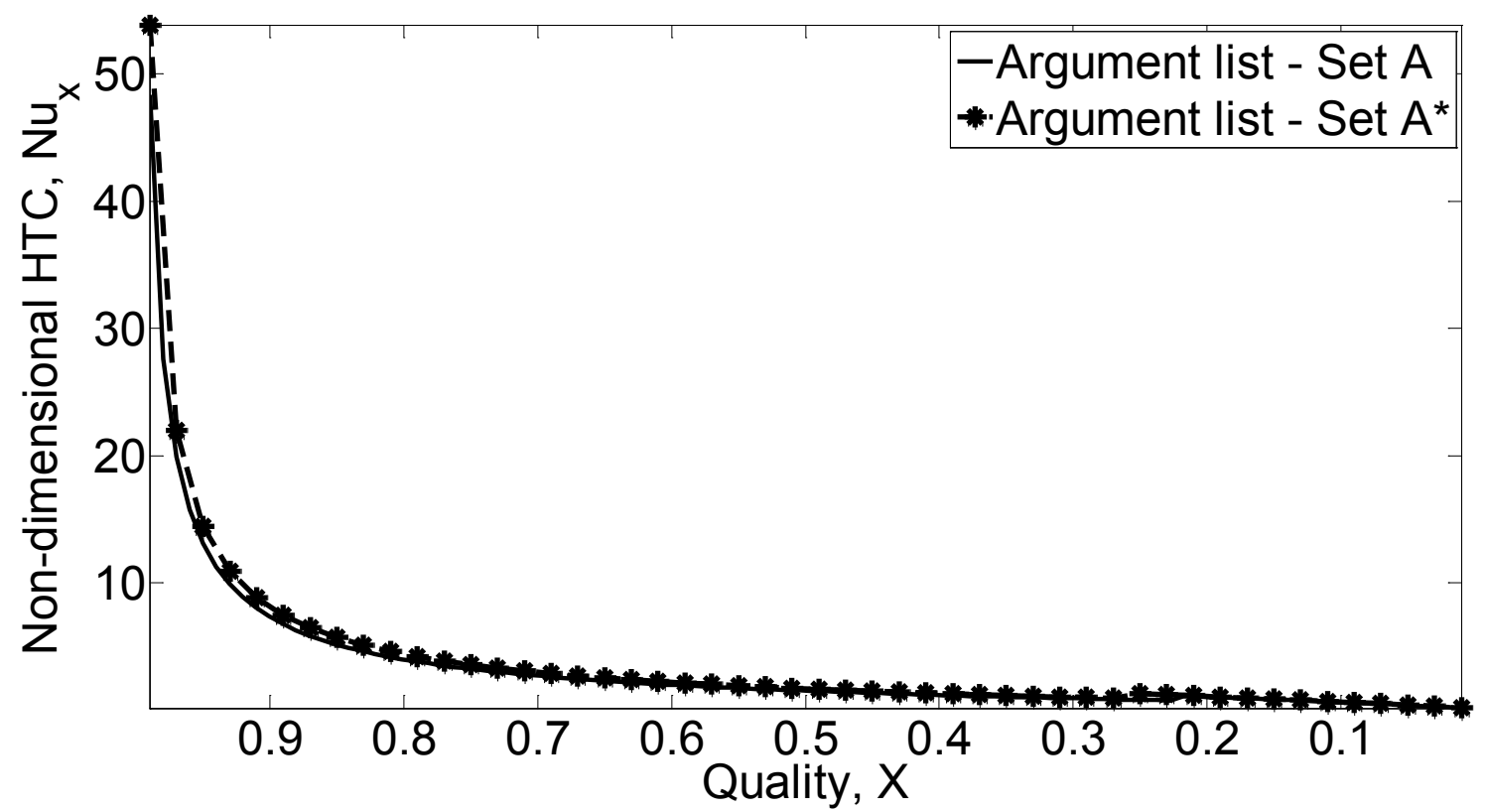

Figure 3.1 Representation of the variation of Nusselt Number with vapor quality for the above mentioned set of flow condition with FC72 as working fluid

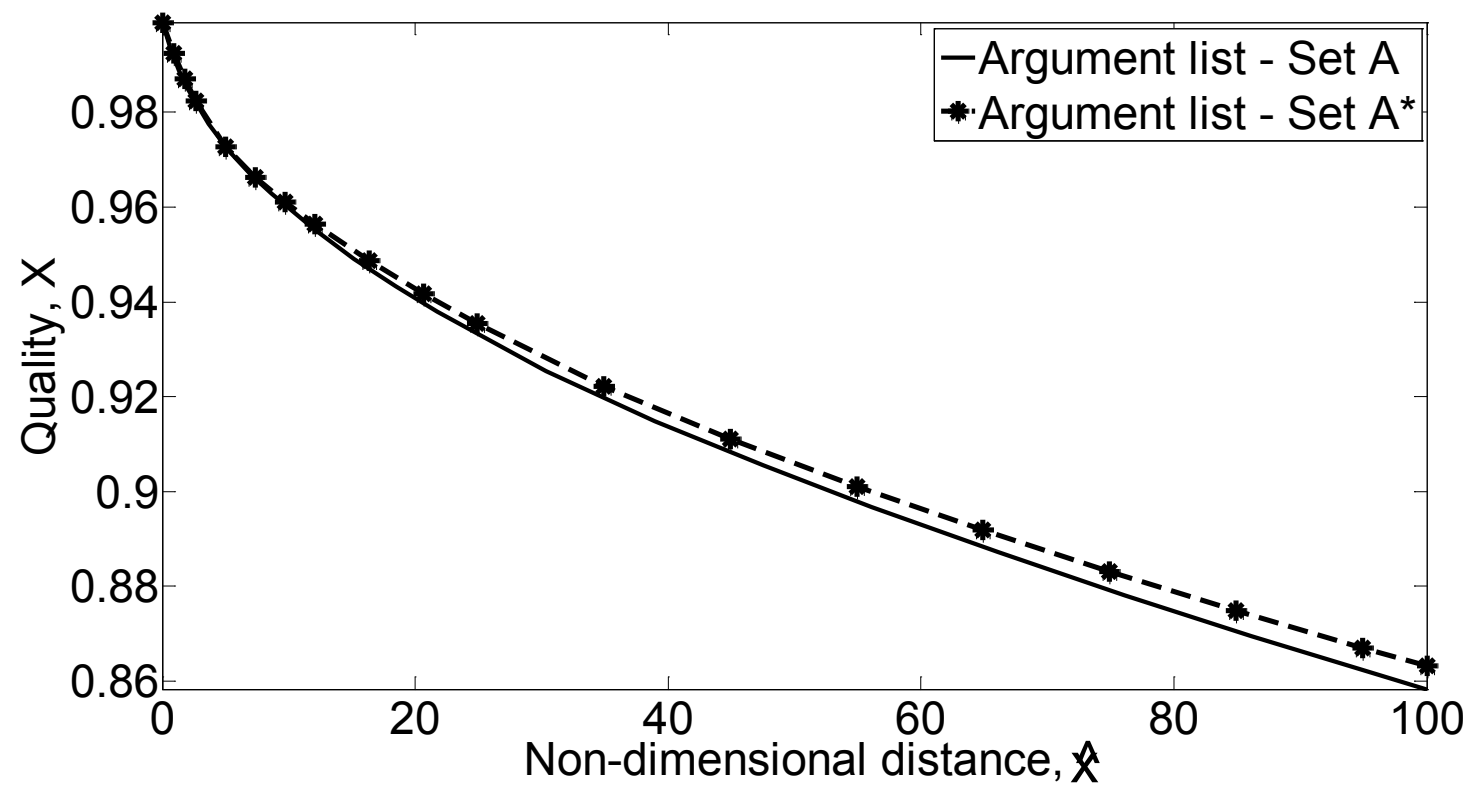

Figure 3.2 Representation of the variation of Vapor Quality with non-dimensional distance for the above mentioned set of flow condition with FC72 as working fluid 
However there are limitations to existing empirical correlations. These limitations are often directly expressed in terms of physical variables rather than non-dimensional set of variables. This study systemizes this approach by first listing raw variables list $\mathbf{A}$ range directly, as in Table 3.1, and then its corresponding list of non-dimensional entities as listed in Table 3.2. This approach of reasonably choosing a boxed zone of boundaries as shown in Figures 3.3 - 3.5 and satisfying them in a proper correlation helps in developing meaningful correlations covering a chosen range of working conditions.

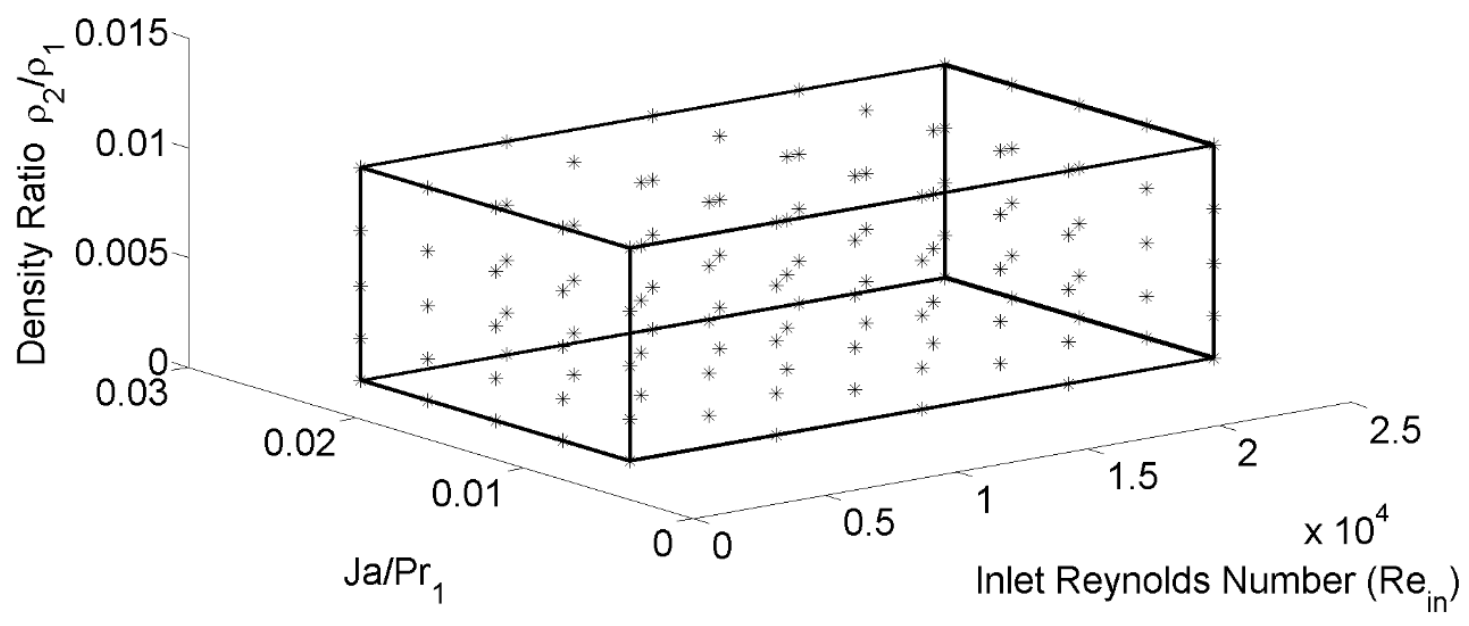

Figure 3.3 Three dimensional parametric space in $\left\{\operatorname{Re}_{\mathrm{in}}, \mathrm{Ja} / \operatorname{Pr}_{1}, \rho_{2} / \rho_{1}\right\}$ 


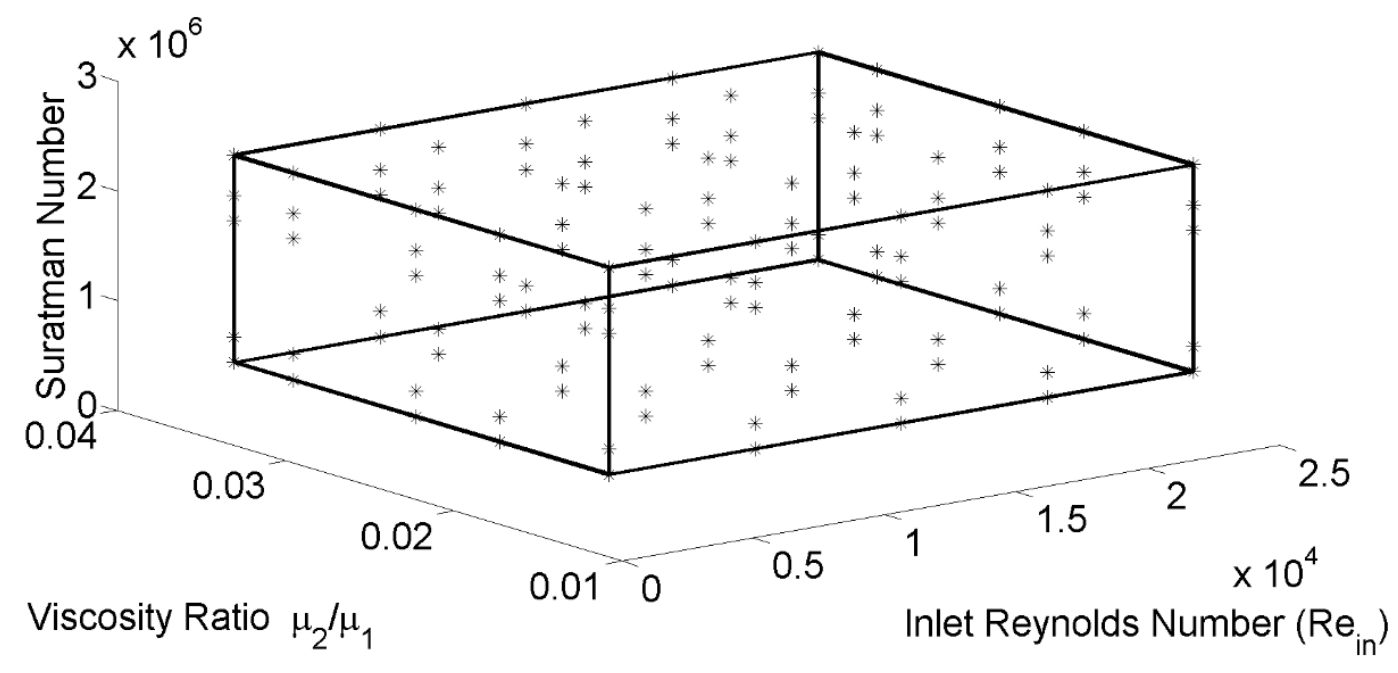

Figure 3.4 Three dimensional parametric space in $\left\{\mathrm{Re}_{\mathrm{in}}, \mu_{2} / \mu_{1}, \mathrm{Su}\right\}$

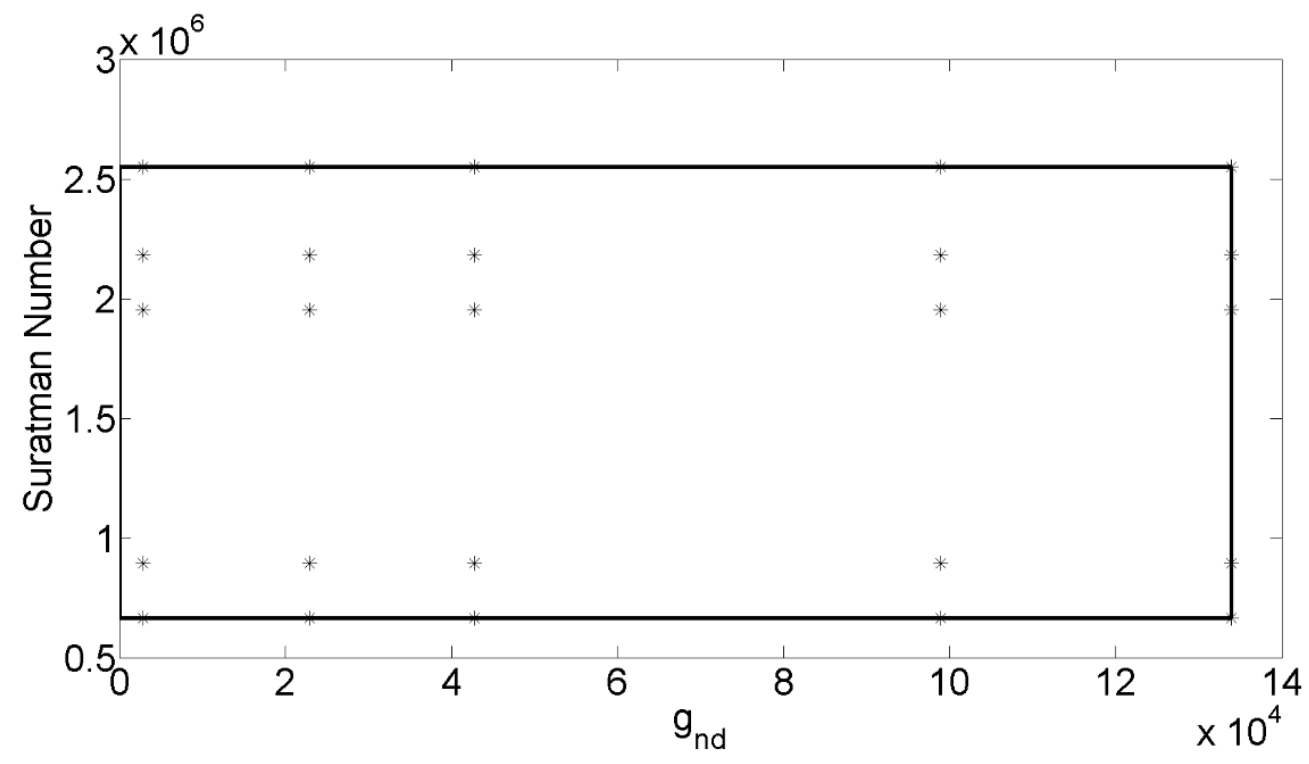

Figure 3.5 Two dimensional parametric space in $\left\{\mathrm{g}_{\mathrm{nd}}, \mathrm{Su}\right\}$ 


\section{Table-3.1}

Range of raw fluid variables and flow conditions considered in this study.

\begin{tabular}{|c|c|c|c|c|}
\hline Working fluids & FC 72 & $\mathrm{R} 113$ & R113 & $\mathrm{R} 134 \mathrm{a}$ \\
\hline Inlet Pressure $(\mathrm{kPa})$ & 100 & 25 & 225 & 150 \\
\hline $\begin{array}{l}\text { Saturation } \\
\text { temperature }\left({ }^{\circ} \mathrm{C}\right)\end{array}$ & 55.94 & 11.1 & 73.86 & -17.15 \\
\hline $\begin{array}{l}\text { Hydraulic Diameter } \\
(\mathrm{h}=0.002 \mathrm{~m})\end{array}$ & $2 \mathrm{~h}$ & $2 \mathrm{~h}$ & $2 \mathrm{~h}$ & $2 \mathrm{~h}$ \\
\hline Transverse Gravity & $0 \leq\left|g_{y}\right| \leq g$ & $0 \leq\left|g_{y}\right| \leq g$ & $0 \leq\left|g_{y}\right| \leq g$ & $0 \leq\left|g_{y}\right| \leq g$ \\
\hline $\begin{array}{l}\text { Inlet Vapor Speed } \\
(\mathrm{U})(\mathrm{m} / \mathrm{s})\end{array}$ & $0.35-9.79$ & $\begin{array}{l}2.07 \quad- \\
57.16\end{array}$ & $\begin{array}{l}0.35 \\
9.79\end{array}$ & $0.54-14.9$ \\
\hline$\Delta \mathrm{T}\left({ }^{\circ} \mathrm{C}\right)$ & $\begin{array}{ll}2.93 & - \\
12.30 & \end{array}$ & $\begin{array}{l}8.69 \quad- \\
36.50\end{array}$ & $\begin{array}{l}2.25 \\
9.45\end{array}$ & $\begin{array}{l}3.45 \\
14.45\end{array}$ \\
\hline
\end{tabular}

\section{Table-3.2}

Range of non-dimensional parameters associated with raw flow variables.

\begin{tabular}{|c|c|c|c|c|}
\hline 800 & $\leq$ & $\mathrm{Re}_{\text {in }}$ & $\leq$ & 23000 \\
\hline 0.005 & $\leq$ & $\mathrm{Ja} / \mathrm{Pr}_{1}$ & $\leq$ & 0.021 \\
\hline 0.0013 & $\leq$ & $\rho_{2} / \rho_{1}$ & $\leq$ & 0.011 \\
\hline
\end{tabular}




\begin{tabular}{|c|c|c|c|c|}
\hline 0.012 & $\leq$ & $\mu_{2} / \mu_{1}$ & $\leq$ & 0.0343 \\
\hline $6.63 * 10^{5}$ & $\leq$ & $\mathrm{Su}$ & $\leq$ & $2.55^{*} 10^{6}$ \\
\hline 0 & $\leq$ & $\mathrm{g}$ nd & $\leq$ & $1.33^{*} 10^{5}$ \\
\hline & & & & \\
\hline
\end{tabular}




\section{Results, Discussions and Conclusions}

\subsection{Computationally derived correlations for heat transfer rates, quality, and the}

length of the annular regime.

This study processes solutions of 1D approximated governing equations for the stratified annular flow regime conditions. These solutions are obtained within the parameter space defined in Table. 3.1 - 3.2. Although 1D solution is sufficiently accurate despite some underlying approximations, 2D steady simulation solutions were used to validate and supplement the 1D solutions. The correlations are presented as a function of nondimensional parameters and using natural log of the computed values of flow variables and non-dimensional numbers, linear regression analysis with least square fits are attempted for dependence such as those given in Eqn. (2.29)- (2.30). These correlations provide a better quality processed information as the flow regime under consideration. Furthermore it outlines a superior approach for creating such correlations for other flow conditions.

\subsubsection{Variation of Nusselt number as a function of non-dimensional distance}

Based on the parameter space defined by the flow variables in this study's Table 3.1 several simulation cases were run and the data were used to correlate the dependence of Nusselt Number on the non-dimensional distance along the length of the condenser and other relevant non dimensional numbers. The result is: 
$\mathrm{Nu}_{\mathrm{x}}=0.113 \hat{\mathrm{x}}^{-0.433} \operatorname{Re}_{\mathrm{in}}^{0.503}\left(\frac{\mathrm{Ja}}{\mathrm{Pr}_{1}}\right)^{-0.308}\left(\frac{\rho_{2}}{\rho_{1}}\right)^{-0.537}\left(\frac{\mu_{2}}{\mu_{1}}\right)^{0.443}$

The linear regression fit was obtained from the computed values obtained from a suitable but large number of simulation runs. The above correlation exhibited with an average error percentage of $5.7 \%$ in the calculation of Nusselt number as long as the process remained within the domain defined in Table 3.2 .

\subsubsection{Prediction of the non-dimensional distance along the length of the condenser as a function of the flow variables}

Similar to the Nusselt number equation, using a 2D approach and relating the length of the annular regime to signatures in the $1 \mathrm{D}$ steady solution $[20,21]$ we could also predict the variation in the non-dimensional annular length for the shear driven condenser. As mentioned earlier this study focuses on the shear driven condensing flow and implements a 1D approximation tool for predicting the results. The effect of transverse gravity is described in $[20,21]$ and is out of scope of this study. This study assumes zero transverse gravity obtaining the correlation for the non-dimensional annular length. However detailed discussion of the effects of the transverse gravity can be obtained from [3, 19$21]$.

$\hat{\mathrm{x}}_{\mathrm{A}}=(0.0155) * \operatorname{Re}_{\mathrm{in}}^{0.9616}\left(\frac{\mathrm{Ja}}{\mathrm{Pr}_{1}}\right)^{-1.1859}\left(\frac{\rho_{2}}{\rho_{1}}\right)^{0.4425}\left(\frac{\mu_{2}}{\mu_{1}}\right)^{0.3}$ 
The above correlation has an average correlation error of $6.433 \%$ in the calculation of the annular length which is considered to be a good fit because of the large number of simulation runs used to obtain the correlation.

\subsubsection{Vapor quality variation dependence on the non-dimensional distance}

The vapor quality dependence on the Nusselt number as explained earlier in Section (2) can be used to obtain a correlation for vapor quality from the Nusselt number correlation (dependent on the non-dimensional distance). The resulting equation is represented below:

$\mathrm{X}(\hat{\mathrm{x}}) \cong 1-0.81 \hat{\mathrm{x}}^{0.73} \operatorname{Re}_{\mathrm{in}}^{-0.64}\left(\frac{\mathrm{Ja}}{\mathrm{Pr}_{1}}\right)^{1.02}\left(\frac{\rho_{2}}{\rho_{1}}\right)^{-0.33}\left(\frac{\mu_{2}}{\mu_{1}}\right)^{-0.86}$

\subsubsection{Physics based support for the correlations dependent on quality}

As mentioned earlier in the representation of the vapor quality correlation, this dependence is used to eliminate physical distance to obtain the Nusselt Number correlation which is dependent on the vapor quality. This is possible because vapor quality has one to one correspondence with the non-dimensional physical distance. Nusselt number dependence on the quality, preferred in engineering correlations to reduce depends on the "method of cooling", is thus obtained and reported as:

$\mathrm{Nu}_{\mathrm{x}} \equiv 0.1001(1-\mathrm{X})^{-0.59} \operatorname{Re}_{\mathrm{in}}^{0.122}\left(\frac{\mathrm{Ja}}{\mathrm{Pr}_{1}}\right)^{0.30}\left(\frac{\rho_{2}}{\rho_{1}}\right)^{-0.73}\left(\frac{\mu_{2}}{\mu_{1}}\right)^{0.069}$ 
The dependence on of Nusselt number on $\frac{\mathrm{Ja}}{\mathrm{Pr}_{1}}$, after the introduction of quality as a parameter has diminished significance in the given parameter space defined in Table 3.2. And hence this correlation can be replaced by a single average constant term, which then simplifies to:

$\mathrm{Nu}_{\mathrm{x}} \equiv 0.031(1-\mathrm{X})^{-0.59} \operatorname{Re}_{\mathrm{in}}^{0.122}\left(\frac{\rho_{2}}{\rho_{1}}\right)^{-0.733}\left(\frac{\mu_{2}}{\mu_{1}}\right)^{0.069}$

These correlations are significantly dependent on the domain of parametric space mentioned earlier in Table 3.1 and, furthermore the assessment of these correlations relative to other correlations is explained in the following figures. The illustrated comparisons are for the specific case of condensing flow with FC72 as the working fluid.

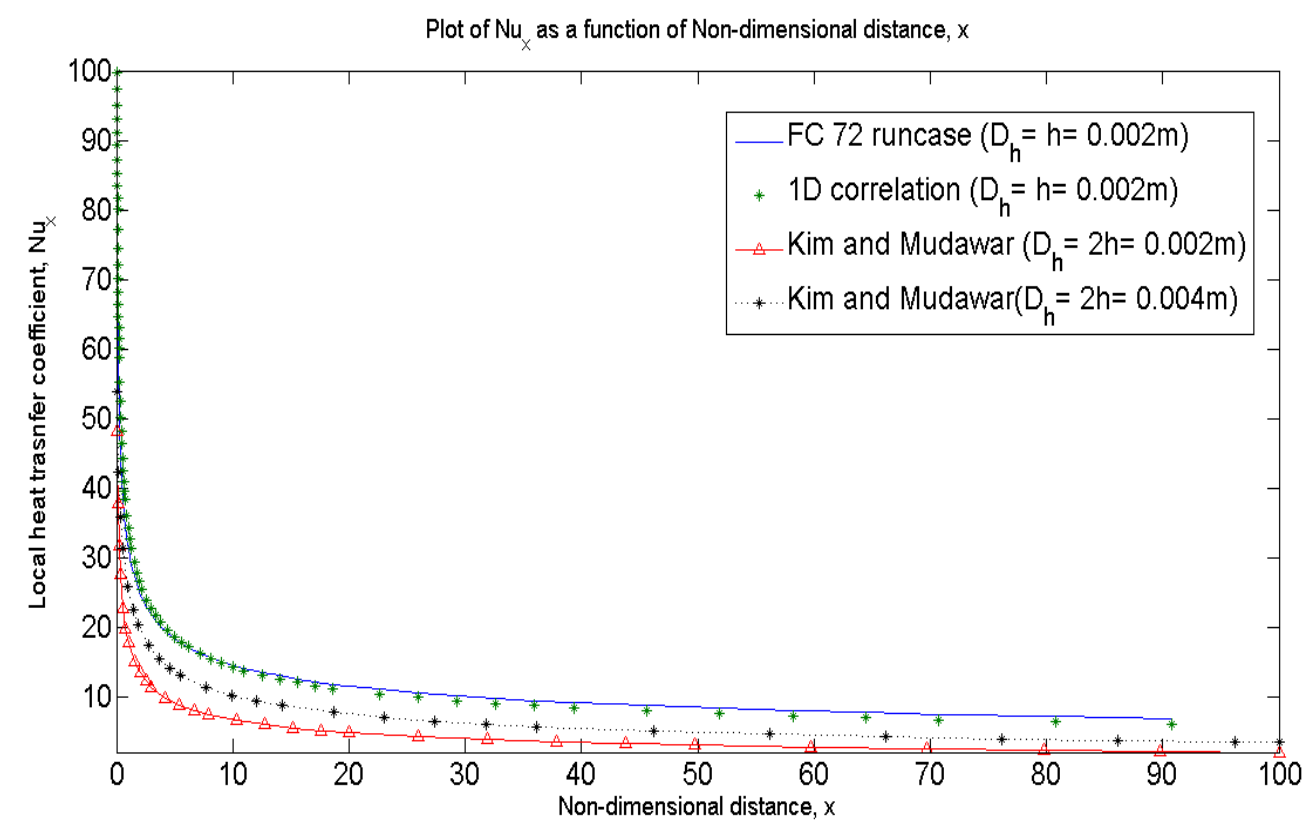

Figure 4.1 Variation of Nusselt Number along the non-dimensional length of the condenser 


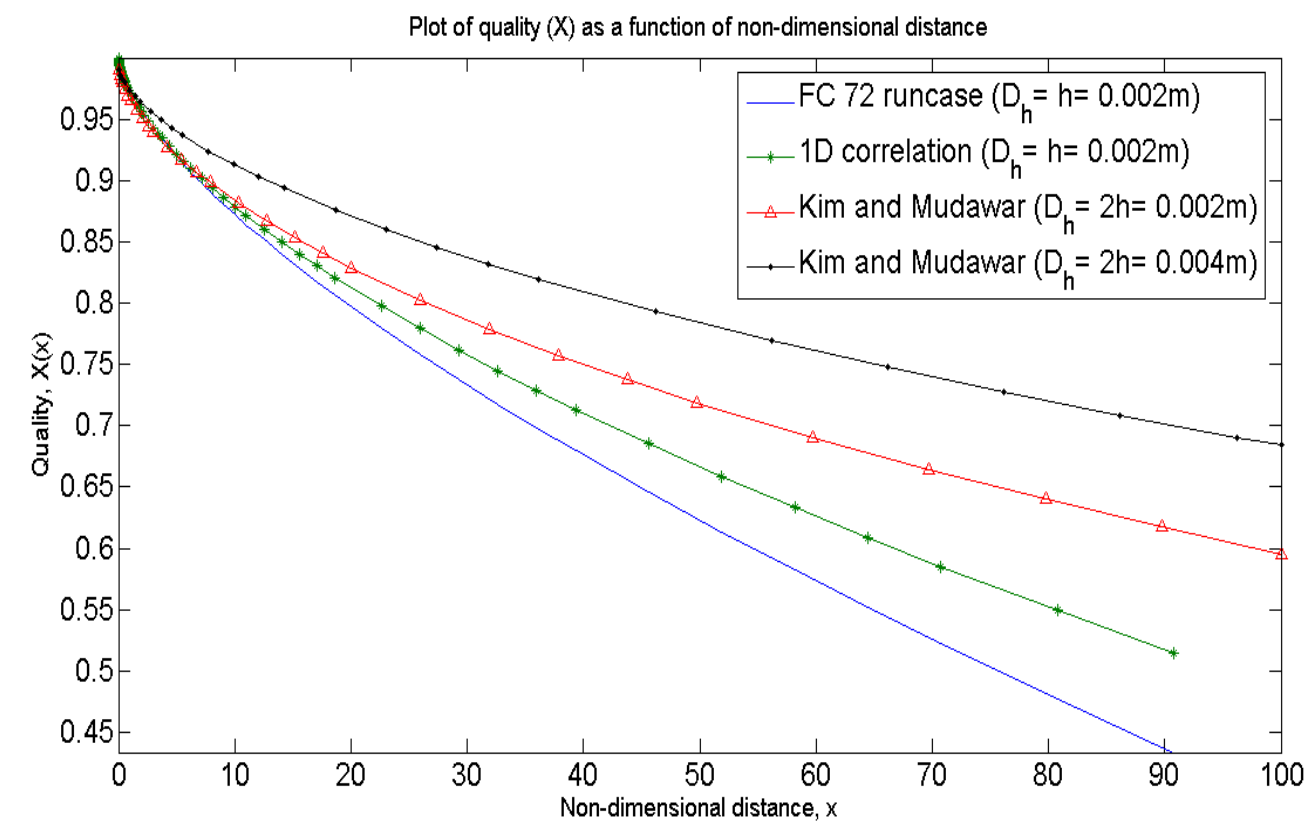

Figure 4.2 Variation of Vapor Quality along the non-dimensional length of the condenser

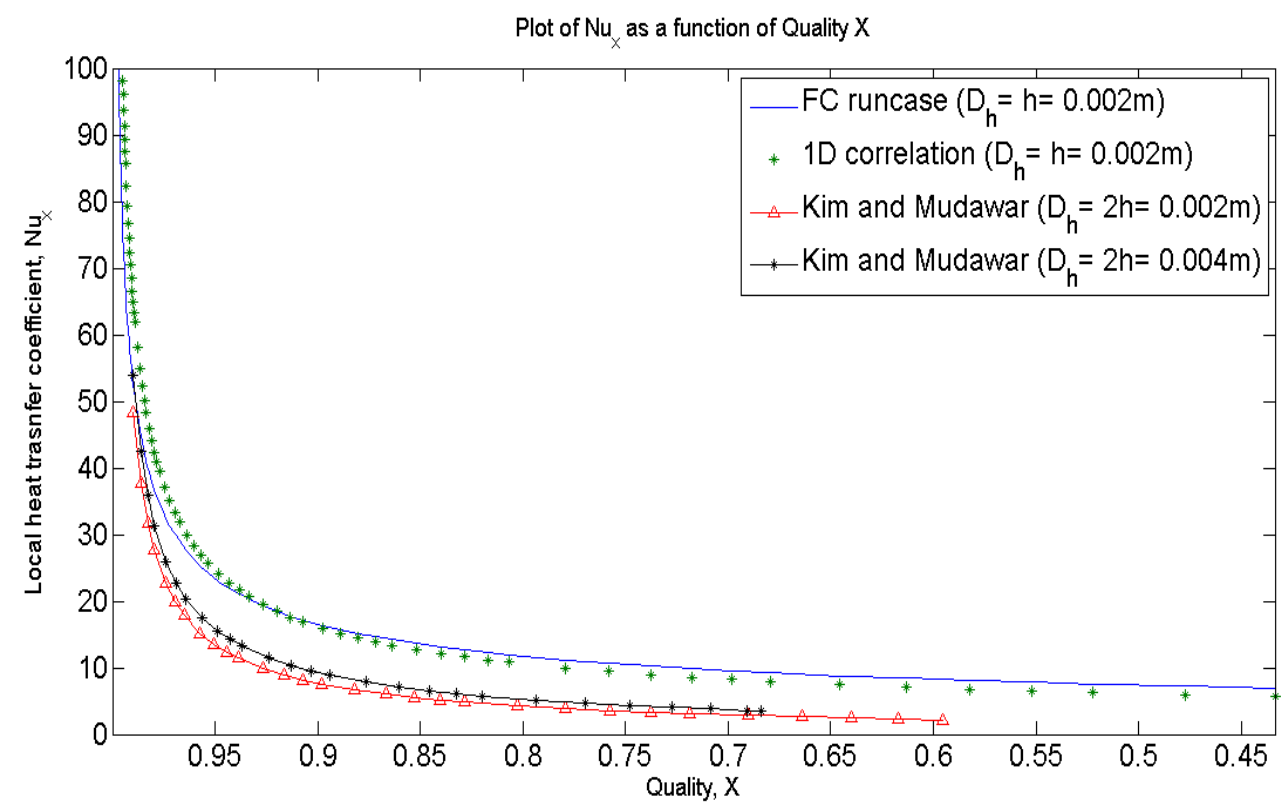

Figure 4.3 Variation of Nusselt Number with the vapor quality 
These pictures depict the variation of the Nusselt Number for a particular case with quality $\mathrm{X}$ flow from simulations, proposed correlations and relevant engineering correlations. The proposed correlations agrees quite well with the universally accepted correlation of Kim and Mudawar [11] which was produced after incorporating to a large volume of experimental data provided by many investigations listed in the paper. This strengthens the reliability of our length of annular regime correlations reported here and in [3] as such information are not extensively available in the experimental literature.

\subsection{Conclusions and Subsequent Research}

The correlations proposed (subject to improvement) in this study for the millimeter scale shear driven condensing flows, are unique and further promote the cause of refined development of correlations based on a synthesis of systematic physics based approach and an empirical approach. The approach elucidates the interdependence of the quality based correlation (with the help of 1D energy equation solver) with those based on direct

physical distance based results obtained from CFD. This helps in understanding the nature of flow through variables that are directly concerned with flow physics and helps in selecting from a large set of existing semi-empirical correlations available in literature. This bridges the gap that exists in understanding, relevance and blind use of existing semi-empirical correlations for heat transfer rates and flow regime maps. 
These correlations are primarily based on the 1D approximation of the governing equations (with support from 2D steady and unsteady solutions [20, 21] for identifying the length of the annular regime), and provide a good initial assessment of any shear driven flow under consideration. The results also provide a strong foundation for further development of correlations for flows that allow for turbulence in the vapor phase. Although this study provides some knowledge based correlations for shear driven internal condensing flows, further semi-empirical extensions of these correlations are possible for high heat flux condensers that employ pulsatile flows. The possibility of providing correlations for predicting heat transfer rates for pulsatile cases and turbulence models are being investigated. Integration of these results with existing pressure drop correlations towards identifying/developing superior pressure drop/rise correlations are possible - but outside the scope of this thesis. 


\section{References}

1. A. Narain, R.R.N., S. Ravikumar, S.S. Bhasme, Fundamental Assessments and New Enabling Proposals for Heat Transfer Correlations and Flow Regime Maps for Shear Driven Condensers in the Annular/Stratified Regime. Journal of Thermal Engineering, 2015. 1(4): p. 307-321.

2. Mitra, S., et al., A quasi one-dimensional method and results for steady annular/stratified shear and gravity driven condensing flows. International Journal of Heat and Mass Transfer, 2011. 54(15-16): p. 3761-3776.

3. Naik, R., Development of unsteady two-dimensional computational simulation tools that simulate annular internal condensing flows and characterize interfacial waves, flow stability and flow sensitivity, in Mechanical Engineering Engineering Mechanics 2015, Michigan Technological University: Houghton, MI.

4. Wilson, J.R. Electronics Cooling Depends on Innovative Approaches to Thermal Management. Military \& Aerospace Electronics, 2009.

5. Lasance, C.J.M. and R.E. Simons Advances In High-Performance Cooling for Electronics. Electronics Cooling, 2005. 11. 
6. Carey, V.P., Liquid-vapor phase-change phenomena : an introduction to the thermophysics of vaporization and condensation processes in heat transfer equipment. 2nd ed. 2008, New York: Taylor and Francis. xxii, 742 p.

7. Baker, O., Simaltaneous flow of Oil and Gas. Oil and Gas Journal, 1954. 53: p. 185-215.

8. Coleman, J.W. and S. Garimella, Two-phase flow regimes in round, square and rectangular tubes during condensation of refrigerant R134a. International Journal of Refrigeration-Revue Internationale Du Froid, 2003. 26(1): p. 117-128.

9. El Hajal, J., J.R. Thome, and A. Cavallini, Condensation in horizontal tubes, part 1: two-phase flow pattern map. International Journal of Heat and Mass Transfer, 2003. 46(18): p. 3349-3363.

10. Kim, S.-M. and I. Mudawar, Universal approach to predicting two-phase frictional pressure drop for adiabatic and condensing mini/micro-channel flows. International Journal of Heat and Mass Transfer, 2012. 55(11-12): p. 3246-3261.

11. Kim, S.-M. and I. Mudawar, Review of databases and predictive methods for heat transfer in condensing and boiling mini/micro-channel flows. International Journal of Heat and Mass Transfer, 2014. 77(0): p. 627-652.

12. Taitel, Y. and A.E. Dukler, A model for predicting flow regime transitions in horizontal and near horizontal gas-liquid flow. AIChE Journal, 1976. 22(1): p. 47-55. 
13. Kivisalu, M.T., P. Gorgitrattanagul, and A. Narain, Results for high heat-flux flow realizations in innovative operations of milli-meter scale condensers and boilers. International Journal of Heat and Mass Transfer, 2014. 75(0): p. 381-398.

14. Kivisalu, M.T., et al., Sensitivity of shear-driven internal condensing flows to pressure fluctuations and its utilization for heat flux enhancements. International Journal of Heat and Mass Transfer, 2013. 56(1-2): p. 758-774.

15. Kivisalu, M.T., Experimental Investigation of Certain Internal Condensing Flows, Their Sensitivity to Pressure Fluctuations and Heat Transfer Enhancements, in Mechanical Engineering. 2015, Michigan Technological University.

16. Dobson, M.K. and J.C. Chato, Condensation in smooth horizontal tubes. Journal of Heat Transfer-Transactions of the Asme, 1998. 120(1): p. 193-213.

17. Shah, M.M., A General Correlation for Heat Transfer during Film Condensation inside Pipes. International Journal of Heat and Mass Transfer, 1979. 22: p. 547556.

18. Wang, W.W., Condensation and single-phase heat transfer coefficient and flow regime visualization in micro-channel tubes for HFC-134a. 1999, Ohio State University: Ohio.

19. Naik, R., S. Mitra, and A. Narain, Steady and Unsteady Computational Simulations for Annular Internal Condensing Flows in a Channel, in Proceedings 
of 2014 ASME International Mechanical Engineering Congress and Exposition. 2014: Montreal, Canada.

20. Naik, R., S. Mitra, and A. Narain, Steady and Unsteady Simulations for Annular Internal Condensing Flows. Part I Algorithm and its Accuracy. Submitted to Numerical heat Transfer, Part B, 2015.

21. Naik, R., S. Mitra, and A. Narain, Steady and Unsteady Simuations for Annular Internal Condensing Flows. Part II Instability and Flow regime Transitions. Submitted to Numerical heat Transfer, Part B, 2015.

22. Shankar, N., An Assessment of Flow Regime Maps and a Numerical Heat Transfer Correlation For The Stratified/Annular Regime of Shear-Driven Internal Condensing Flows, in Mechanical Engineering. 2014, Michigan technological University: Houghton.

23. Narain, A., et al., Direct computational simulations for internal condensing flows and results on attainability/stability of steady solutions, their intrinsic waviness, and their noise sensitivity. Journal of Applied Mechanics, 2004. 71(1): p. 69-88.

24. Bruce R. Munson, D.F.Y., Theodore H. Okishii, Fundamentals of Fluid Mechanics. 2012.

25. Liang, Q., X. Wang, and A. Narain, Effects of gravity, shear and surface tension in internal condensing flows: Results from direct computational simulations. Journal of Heat Transfer, 2004. 126(5): p. 676-686. 
26. COMSOL, Multiphysics Tool.

27. Mathworks, MATLAB.

28. Lockhart, R.W. and R.C. Martinelli, Proposed correlation of data for isothermal two-phase, two-component flow in pipes. Chemical Engineering Progress, 1949. 45: p. 39-48. 